\title{
Total and Sustainable Valorisation of Olive Pomace Using a Fractionation Approach
}

\author{
Tânia B. Ribeiro ${ }^{1,2}{ }^{\oplus}$, Ana L. Oliveira ${ }^{1}$, Cristina Costa ${ }^{2}$, João Nunes ${ }^{1}$, António A. Vicente ${ }^{3} \mathbb{C}$ \\ and Manuela Pintado ${ }^{1, *}$ \\ 1 CBQF-Centro de Biotecnologia e Química Fina-Laboratório Associado, Escola Superior de Biotecnologia, \\ Universidade Católica Portuguesa, Rua Diogo Botelho 1327, 4169-005 Porto, Portugal; tribeiro@porto.ucp.pt \\ or tania.ribeiro@blc3.pt (T.B.R.); asoliveirra@porto.ucp.pt (A.L.O.); joao.nunes@blc3.pt (J.N.) \\ 2 Centre Bio R\&D Unit, Association BLC3-Technology and Innovation Campus, Rua Nossa Senhora da \\ Conceição, 2, Lagares, 3405-155 Oliveira do Hospital, Portugal; cristina.costa@blc3.pt \\ 3 Centro de Engenharia Biológica, Universidade do Minho, Campus Gualtar, 4710-057 Braga, Portugal; \\ avicente@deb.uminho.pt \\ * Correspondence: mpintado@porto.ucp.pt; Tel.: +351-22-55-800-44
}

Received: 14 August 2020; Accepted: 23 September 2020; Published: 28 September 2020

\begin{abstract}
Olive pomace management represents a great concern to the olive oil industry. This work focused on the development of a "zero waste" strategy for olive pomace based on a fractionation approach resulting in the obtention of different value-added fractions. The physicochemical composition of edible fractions obtained (liquid and pulp) was analysed. The potential use as a solid biofuel of the non-edible fraction (stones) was evaluated. High amounts of hydroxytyrosol (513.61-625.76 mg/100 g dry weight) were present in the liquid fraction. Pulp fraction was demonstrated to be a good source of fibre (53-59\% dry weight) with considerable antioxidant activity both from free and bound phenolics. The stones fraction exhibited substantial high heating values (18.65-18.94 megajoule (MJ/kg). All these results support the added value of the olive pomace fractions combining the biofuel potential from the stones fraction and the functional food ingredients' potential both from liquid and pulp fractions. The present methodology seems to be a feasible whole valorisation approach to achieve the circularity in the olive oil sector, prioritising obtaining high over low added-value products.
\end{abstract}

Keywords: olive pomace; valorisation; fractionation; food ingredients; solid biofuel; hydroxytyrosol

\section{Introduction}

The reduction and valorisation of by-products is one of the biggest challenges of the food industry. Nowadays, there is an increasing concern for the achievement of a more sustainable food production chain, specifically, in reducing the environmental impact of its by-products or the costs associated with its proper treatment [1]. Besides the economic and environmental consequences, there is also an ethical and moral dimension within the general concept of global food security, since 805 million people across the globe suffer from hunger [2].

These negative impacts are even more flagrant in growing industries, like the olive oil industry (mainly in the Mediterranean countries), that produce large quantities of by-products and wastes $[1,3]$. Portugal is one of the Mediterranean countries where olive oil production has been rising (with an estimated increase of 30\% in olive oil production in 2019 compared to the 2018 campaign) [4], which also implies the treatment of more tonnes of waste. Between all the wastes and by-products of the olive industry, the olive pomace is the most representative [5]. Olive pomace is a combination of olive husk and pulp, crushed olive stone and olive mill wastewater with a moisture content of 65\% [6] that derives from the modern two-phase extraction method, in which no water is added (more eco-friendly than the three-phase process) [7]. 
Olive pomace is phytotoxic and non-biodegradable biomass [8] that is challenging to treat due to its richness in moisture (higher energy demand and consequently higher costs during the drying process) and organic compounds (adverse effects on soil) [9]. Nonetheless, olive pomace is also a significant source of bioactive compounds like fibre [10], minerals, polyunsaturated fatty acids and phenolic compounds [5].

Commonly, olive pomace is sent to pomace oil extraction mills, in which, after a drying process, it is used to extract oil using hexane. This process generates pomace oil but also dried pomace that is mainly used as a solid fuel [3] due to its high calorific power [11]. However, dried olive pomace contains oil residues and principally low-weight particles (pulp and olive stones $<1 \mathrm{~mm}$ ), which are considered to be harmful compounds related to uncontrolled emission, corrosion and slagging, compromising the performance of olive pomace as solid biofuel [12]. To a lesser extent, olive pomace can also be composted to avoid the harmful effects of the organic compounds and used as a fertiliser [9], or even used to generate or cogenerate electricity [13]. However, these traditional olive pomace treatments were considered a wastage of bioactive compounds with high value-added, as these treatments are not the most sustainable options because of their use of solvents and high carbon dioxide equivalent $\mathrm{CO}_{2 \text {-eq }}$ emissions $[9,13]$. Besides, under the aim of a transition from a non-sustainable linear economy ('take-make-dispose of') to a circular bioeconomy (maintain the value of products and materials for as long as possible while minimising resource use and waste generation) of the olive oil sector, higher-value uses should be prioritised over the current energy and compost valorisation [14].

Bioactive compounds of olive pomace have been described as potent food antioxidants and antimicrobials and can even contribute to the prevention of chronic diseases such as cardiovascular disease and cancer [7]. Having this in consideration, olive pomace should be firstly employed as food source ingredients and only after as an energy generator [14].

The adoption of valorisation approaches to increase the value of olive pomace biomass is a crucial target to permit the olive oil sector to enhance its economic and environmental sustainability. A considerable number of valorisation methods of olive pomace have been studied in the last years, but none of the proposed methods appear to answer entirely to the principal problem. Olive pomace has been explored as a biomass source for biorefineries to produce second-generation ethanol [3], for agricultural use as compost or as irrigation water [8] and as a component in the manufacture of different materials as lightweight aggregates [6]. Additionally, more studies about the recovery of value-added products have been explored using conventional solvent-extraction or non-conventional extraction techniques (e.g., microwave-assisted, enzyme-assisted and supercritical fluid extraction) [15]. Nevertheless, in these previous studies, only low amounts of olive pomace were used, or merely a small fraction was valorised (often phenolic compounds), leaving the majority of olive pomace untreated [16]. Besides that, some of these approaches are not sustainable (the use of water or solvents) or possess high total operational costs [15]. Therefore, more complete, sustainable and economically viable valorisation approaches for olive pomace need to be developed and validated.

One of the obstacles for the achievement of a total olive pomace valorisation scheme is linked to its structural heterogeneity and complexity. Olive pomace is a mixture of water, residual skin, pulp and pieces of the crushed stone [17]. Olive pomace heterogeneity could be the biggest challenge for its valorisation but could also be an advantage to obtain different value-added products from olive pomace. Therefore, the application of a fractionation process appears as a promising alternative for the production of value-added olive pomace fractions without any consumption of water nor chemicals and lower energy consumption during the drying process [18].

The result of the fractionation approach could be producing liquid (L-OP), pulp (P-OP) and stone (S-OP) fractions from crude-olive pomace (C-OP). The stone fraction promises to exhibit the best properties for thermal power generation due to its uniform size and high density [12]. On the other hand, liquid and pulp fractions from olive pomace have potential as food ingredients. It is expected that the liquid fraction might be a source of phenolic compounds such as hydroxytyrosol and derivatives [8], and that the pulp fraction might be a potential source of antioxidant dietary 
fibre [19], i.e., a rich source of fibre and phenolic compounds (free and bound to fibre) [20]. Therefore, the valorisation of these bioactive compounds is required at competitive prices, so that it can be used, for instance, as powdered food ingredients.

In this line, the present work focuses on the use of a fractionation approach (wet and dry fractionation) as an eco-friendly "zero waste" solution to obtain new value-added products from olive pomace. The physiochemical/bioactive properties and calorific potential of the different obtained olive pomace fractions were assessed to validate its potential as valuable ingredients to the energy and food industries. Moreover, the nutritional profile and chemical composition (regarding proximate composition, sugars, fibre composition, free and bound phenolic compounds) of olive pomace were also assessed.

\section{Materials and Methods}

\subsection{Chemicals}

The 2, 2-diphenyl-1-picrylhydrazyl (DPPH), 2, 2'-azo-bis-(2-methylpropionamidine)-dihydrochloride (AAPH), fluorescein, 2, 2-azinobis-3-ethylbenzothiazoline-6-sulphonic acid (ABTS diammonium salt), potassium sorbate, sodium carbonate, ethylenediaminetetraacetic acid (EDTA), sodium sulphite and sodium lauryl sulphate were purchased from Sigma-Aldrich (Sintra, Portugal). Methanol, acetonitrile and sulphuric acid were purchased from Fischer Scientific Portugal. Folin-Ciocalteu's reagent and potassium persulfate were purchased from Merck (Algés, Portugal). Standards of mannitol, glucose, arabinose, mannose, galactose, xylose, galacturonic acid, trolox, gallic acid, vanillin, quercetin, $p$-coumaric, protocatechuic and caffeic acid were purchased from Sigma-Aldrich (Sintra, Portugal), whereas hydroxytyrosol, tyrosol, luteolin and luteolin-7-O-glucoside were obtained from Extrasynthese (Lyon, France).

\subsection{Olive Pomace Samples}

The crude olive pomace was collected from 2 olive mills (OM) with a continuous biphasic extraction system (OM 1 and OM 2) from the Inner Centre Region of Portugal. The main olive cultivar is Galega Vulgar ( $80 \%$ of the olive heritage). The samples were homogenised, packed in polyethene flasks and stored $\left(\right.$ at $\left.-80^{\circ} \mathrm{C}\right)$ until use.

\subsection{Fractionation of Olive Pomace}

Fractionation of the crude olive pomace samples (OM 1 and OM 2) was carried out to produce liquid, pulp and stones fractions following the scheme evidenced in Figure 1. The first step is the wet fractionation by centrifugation (4000 rotation per minute (RPM), $10 \mathrm{~min}$ ) to separate the liquid fraction from the solid, followed by freeze-drying (Telstar Lyo Quest HT 40).

The dry fractionation was applied in the freeze-solid by sieving after a previous milling process with a coffee grinder obtaining the pulp fraction (particle size $<1 \mathrm{~mm}$ ) and the stones fraction (particle size $>1 \mathrm{~mm}$ ). The stone fraction and edible fractions (liquid and pulp fractions) obtained from olive pomace were vacuum-packed and stored in a dark and dry place at room temperature, until use. The crude olive pomace samples were also freeze-dried, milled and sieved as a control. 
OLIVE POMACE FRACTIONATION PROCESS - LAB SCALE

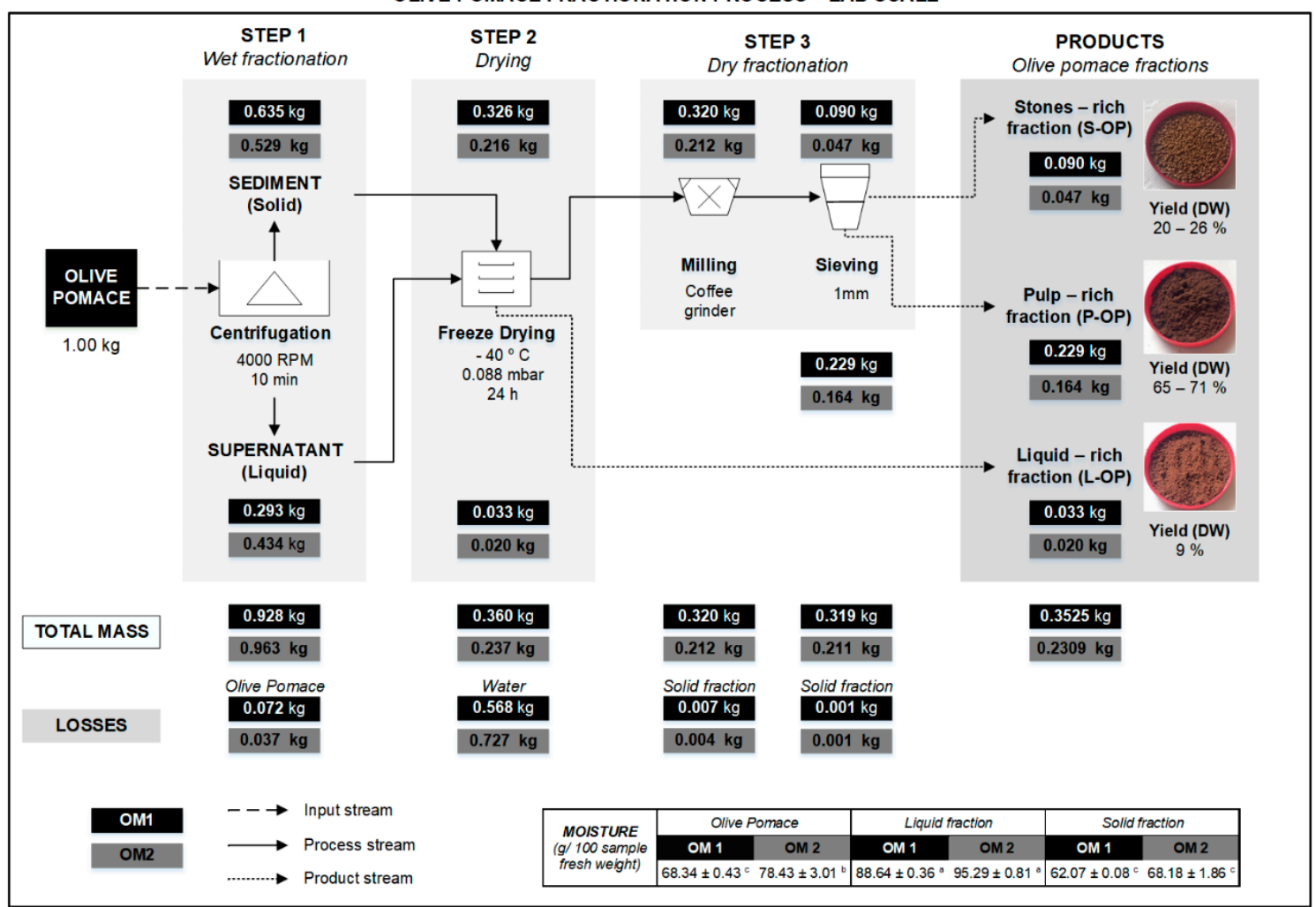

Figure 1. Proposed fractionation process for olive pomace valorisation to achieve maximum value and "zero waste": products and yields. Abbreviations: OM 1-olive mill 1, OM 2-olive mill 2, $\mathrm{C}-\mathrm{OP}-\mathrm{Crude}$ olive pomace, L-OP-liquid-rich fraction, $\mathrm{P}-\mathrm{OP}$ - pulp-rich fraction.

\subsection{Chemical Composition Determination}

\subsubsection{Proximate Composition}

The moisture content (Association of Official Agricultural Chemists (AOAC) No. 934.06) was determined in the fresh and dried samples. The contents in crude fibre (Weende method), crude protein (Kjeldahl method with conversion factor: 6.25), lipid (AOAC 920.39), crude ash (AOAC No. 942.05) and carbohydrate (calculated by difference from crude fibre, moisture, protein, lipid and ash) were estimated in freeze-dried samples. All methodologies followed the recommendations of the Official Methods of Analysis [21]. All analyses were done in triplicate. The chemical compounds were expressed as $\mathrm{g} / 100 \mathrm{~g}$ dry weight (DW).

\subsubsection{Detergent Fibre}

The contents of neutral detergent fibre (NDF) and acid detergent fibre (ADF) were determined by the method of Goering and Van Soest [22] NDF measures all insoluble cell wall material, including hemicelluloses, cellulose and lignin, and ADF measures cellulose and lignin.

\subsubsection{Cellulose, Hemicellulose and Lignin}

For cellulose (as glucose), hemicellulose (as arabinose, mannose, galactose and xylose) and lignin (soluble and insoluble) determination of crude olive pomace, liquid and pulp fraction samples, the methodology of Sluiter et al. [23] was followed. Previously, the removal of extractives was carried out using a Soxhlet extraction system (SER 148, Velp, Usmate Velate MB, Italy) using ultrapure water and absolute ethanol as solvents in two sequential stages [24]. Then, the free-extractives samples were submitted to two-step sequential acid hydrolysis and further determination/quantification of the 
cellulose, and hemicellulose content was achieved using high-performance liquid chromatography (HPLC). Structural carbohydrates were determined by HPLC (micro guard column: Aminex Carbo-P, Bio-Rad; carbohydrate analysis column: Aminex HPX-87P heavy metal, $300 \times 7.8 \mathrm{~mm}$, Bio-Rad; flow rate: $0.6 \mathrm{~mL} / \mathrm{min}$; detector: refractive index) and were used to calculate the cellulose (as glucose) and hemicellulose (as arabinose, mannose, galactose and xylose) content [23]. The insoluble lignin content was calculated gravimetrically after hydrolysis residue filtration, and soluble lignin was estimated by ultraviolet (UV) spectrophotometry at $340 \mathrm{~nm}$ [23]. The results were expressed in g/100 g DW.

\subsubsection{Extractable Pectins}

Extractable pectins from the crude olive pomace, liquid and pulp fraction samples were fractionated into water-soluble pectin, chelator-soluble pectin and hydroxide-soluble pectin and quantified, according to Deng et al. [25]. First, $1.0 \mathrm{~g}$ of the sample was homogenised in $20 \mathrm{~g}$ of deionised water for $10 \mathrm{~min}$. The homogenate was filtrated (Whatman No. 1 filter paper) and the retentate and filtrate were collected. Water-soluble pectin was determined as the precipitate that resulted from the addition of $95 \%$ ethanol to the filtrate (1:5) and then allowing it to stand overnight in a refrigerator. Chelator-soluble pectin was determined from the water-extracted residue, by boiling the residue with $95 \%$ ethanol for $10 \mathrm{~min}$, followed by 3 successive extractions of the resulting residue with $50 \mathrm{~mL}$, $20 \mathrm{mM} \mathrm{Na}_{2}$-EDTA and $\mathrm{pH}$ 8.0. Following each extraction, the suspension was filtered, and the filtrates were combined. The residue obtained from the $\mathrm{Na}_{2}$-EDTA extractions was subsequently extracted with $50 \mathrm{mM} \mathrm{NaOH}(50 \mathrm{~mL})$ for $15 \mathrm{~min}$ at room temperature, the suspension was filtered, and the filtrate was collected for measurement of hydroxide-soluble pectin. The referred quantification was based on a colorimetric assay (AOAC 994.13, 2007) using galacturonic acid for determination of the calibration curve. Briefly, $250 \mu \mathrm{L}$ boric acid-sodium chloride solution (content) and $250 \mu \mathrm{L}$ of the sample (or standard) were mixed with $4 \mathrm{~mL}$ of $96 \% \mathrm{H}_{2} \mathrm{SO}_{4}$ and incubated at $70{ }^{\circ} \mathrm{C}$ for $40 \mathrm{~min}$. Afterwards, $200 \mu \mathrm{L}$ of dimethylphenol reagent (100 mg of 3, 5-dimethylphenol in $100 \mathrm{~mL}$ of glacial acetic acid) was added and mixed, and the absorbance of the resulting solution was measured at 400 and $450 \mathrm{~nm}$, respectively [25]. Water-soluble, chelator-soluble and hydroxide-soluble pectins were quantified as galacturonic acid equivalents (GUAE).

\subsubsection{Soluble Sugars}

The soluble sugars were estimated in ultra-pure water extractives using the phenol-sulphuric acid method for total carbohydrates [26]. The sugar content was determined by thoroughly mixing $80 \mu \mathrm{L}$ of the soluble sugar-containing solution with $2 \mathrm{~mL} 98 \% \mathrm{H}_{2} \mathrm{SO}_{4}$ and $320 \mu \mathrm{L}$ phenol $5 \%$, incubating the reaction mixture for $15 \mathrm{~min}$ at $100{ }^{\circ} \mathrm{C}$, cooling (room temperature), and measuring absorbance at $490 \mathrm{~nm}$, using a calibration curve obtained with D-(+)-glucose. Results were expressed as g glucose equivalents/100 $\mathrm{g}$ DW. Free sugar profiles were determined by HPLC coupled to a refraction index detector using an Aminex 87- $\mathrm{H}$ column (Bio-Rad, Berkeley, CA, USA) at $55^{\circ} \mathrm{C}$ and $35 \mathrm{mM} \mathrm{H}_{2} \mathrm{SO}_{4}$ as mobile phase (flow rate: $0.5 \mathrm{~mL} / \mathrm{min}$ ) [27]. Sugar identification was achieved by comparison of the retention times of sample peaks with glucose and mannitol standards. The results were expressed in $\mathrm{g} / 100 \mathrm{~g} \mathrm{DW}$.

\subsection{Structural Characterisation}

\section{Chemical Groups and Bonding Arrangement of Constituents}

Fourier-transform infrared spectroscopy (FTIR) spectra of crude olive pomace and fraction samples (liquid, pulp and pulp fraction extractives-free) were recorded using an IRAffinity-1S, Shimadzu. The spectra were collected through the wavenumber range of 600 to $4000 \mathrm{~cm}^{-1}$, with a resolution of $4 \mathrm{~cm}^{-1}$ for 50 scans. The resulting spectra were baseline-corrected and analysed using Origin Lab software. 


\subsection{Bioactive Characterisation}

\subsubsection{Free and Bound Phenolic Compounds}

The extracts of free phenolic compounds were obtained according to the Alu'datt et al. [20] with some modifications. Samples (1.5 g) of crude olive pomace, liquid and pulp fraction samples were extracted on an orbital shaker (250 RPM) using methanol $(25 \mathrm{~mL})$ for $60 \mathrm{~min}$ (twice), followed by centrifugation (4000 RPM, $10 \mathrm{~min}$ ) and supernatant recuperation. The extraction of bound phenolic compounds was achieved according to Xie et al. [28] with some adaptations. The extraction residue was hydrolysed for $4 \mathrm{~h}(20 \mathrm{~mL}$ of $4 \mathrm{M} \mathrm{NaOH}$ on an orbital shaker at $250 \mathrm{RPM})$ followed by acidification to pH 1.5-2.0 using $6 \mathrm{M}$ hydrocloric acid $(\mathrm{HCl})$. After 30 min of centrifugation (8000 RPM), the supernatant was extracted 5 times with ethyl acetate $(30 \mathrm{~mL})$. The ethyl acetate was dried using anhydrous $\mathrm{Na}_{2} \mathrm{SO}_{4}$ and evaporated to dryness using a rotary vacuum evaporator at $30^{\circ} \mathrm{C}$. The resulting residue was subsequently dissolved in methanol to a final volume of $10 \mathrm{~mL}$. The free and bound phenolic extracts obtained were stored at $-20^{\circ} \mathrm{C}$ until use.

The total phenolic content (TPC) of free and bound phenolic extracts was determined according to the Folin-Ciocalteu's method [29]. Briefly, $50 \mu \mathrm{L}$ of the methanolic extract was mixed with $50 \mu \mathrm{L}$ Folin-Ciocalteu's reagent, $1 \mathrm{~mL}$ of $\mathrm{Na}_{2} \mathrm{CO}_{3}(75 \mathrm{~g} / \mathrm{L})$ and $1.4 \mathrm{~mL}$ of ultra-pure water. The reaction tubes were incubated for $60 \mathrm{~min}$ at room temperature in the dark. The absorbance of the reaction mixtures was measured at $750 \mathrm{~nm}$ using gallic acid as a standard. All analyses were performed in triplicate. Results were expressed as mg gallic acid equivalents (GAE)/g DW.

To identify the phenolic compounds, the extracts were analysed in an liquid chromatography electrospray ionization quadrupole time-of-flight mass spectrometry (LC-ESI-UHR-QqTOF-MS) system (Bruker Daltonics, Billerica, MA, USA) following the methodology of Monforte, Martins and Ferreira [30], with some modifications in the gradient elution program (mobile phase A: $0.1 \%$ aqueous formic acid and mobile phase B: acetonitrile with $0.1 \%$ formic acid) to obtain a good separation of phenolic compounds: 0-5 min (5\% B), 5-25 min (15\% B), 25-35 min (30\%), 35-40 $\min (95 \%$ B), $40-41$ $(5 \% \mathrm{~B})$ and $41-42 \mathrm{~min}(0 \% \mathrm{~B})$. Identification of the main phenolic compounds was based on standard solutions retention time, UV-Vis and mass spectra, when available. The other peaks were tentatively identified based on the literature, and their elemental composition was confirmed according to accurate mass (within $5 \mathrm{mDa}$ of the assigned elemental composition) and isotope rate calculations designated mSigma (mSigma values $<20$ ). The main phenolic compounds identified were quantified by HPLC (Waters e2695 separation module system interfaced with a Photodiode array UV/V is detector) using external calibration curves constructed based on their maximum UV signal (280, 320 and $360 \mathrm{~nm})$ following Oliveira et al.'s [31] procedure. The separation was performed in a reverse-phase column (COSMOSIL 5 C1 8-AR-II packed column—4.6 mm Inner Diameter. $\times 250$ mm; Dartford, UK).

Sample and standard solutions were analysed using a solution of water/acetonitrile $(95: 5 \mathrm{v} / \mathrm{v})$ with $0.2 \%$ trifluoroacetic acid (TFA) was used as mobile phase A, while mobile phase B was constituted of acetonitrile $(100 \%)$ with gradient program at a flow rate of $1 \mathrm{~mL} / \mathrm{min}: 0-2 \mathrm{~min}(100 \% \mathrm{~A}), 2-28 \mathrm{~min}$ $(60 \% \mathrm{~A})$ and $28-30 \mathrm{~min}(100 \% \mathrm{~A})$. [31]. Identification of the main phenolic compounds (3-hydroxytyrosol, protocatechuic acid, tyrosol, oleuropein, luteolin-7-O-glucoside, caffeic acid, rutin hydrate, p-coumaric acid, luteolin and quercetin) in methanol was performed by comparison of retention times, spectra and peak areas at maximum absorption wavelength. The results of the main phenolic compounds were expressed as $\mathrm{mg} / 100 \mathrm{~g}$ DW.

\subsubsection{Antioxidant Activity}

The free and bound phenolic extracts were used to evaluate the radical scavenging capacity of crude olive pomace, liquid and pulp fraction samples according to 3 methods: DPPH [32], ABTS [33] and Oxygen Radical Absorbance Capacity (ORAC) [29]. In the DPPH method, $1.75 \mathrm{~mL}$ of a $60 \mu \mathrm{M}$ DPPH methanolic solution was added to $250 \mu \mathrm{L}$ of sample and incubated at $30^{\circ} \mathrm{C}$ for $1 \mathrm{~h}$. The results were obtained by absorbance measurement at $515 \mathrm{~nm}$ in a spectrophotometer. ABTS was generated 
through a chemical oxidation reaction with potassium persulfate [33]. The concentration of ABTS radical was adjusted with methanol to an initial absorbance of $0.700 \pm 0.020$ at $734 \mathrm{~nm}$. To $200 \mu \mathrm{L}$ of this solution of ABTS, $20 \mu \mathrm{L}$ of the sample, Trolox or solvent were added, using a 96-well plate. The mixture was incubated $\left(30^{\circ} \mathrm{C}\right)$ for $5 \mathrm{~min}$, and the absorbance at $734 \mathrm{~nm}$ was measured with a microplate reader. In the ORAC assay, the reaction was carried out at $40^{\circ} \mathrm{C}$ in $75 \mathrm{mM}$ phosphate buffer (pH 7.4), and the final assay mixture $(200 \mathrm{~mL})$ contained fluorescein $(70 \mathrm{nM})$, AAPH $(14 \mathrm{mM})$ and antioxidant (Trolox or sample, at different concentrations). The fluorescence was recorded during $137 \mathrm{~min}$ (104 cycles) in a FLUO star OPTIMA plate reader (BMG Labtech, Offenburg, Germany) with $485 \mathrm{~nm}$ excitation and $520 \mathrm{~nm}$ emission filters. The equipment was controlled by the FLUO star Control software version (1.32 R2) for fluorescence measurement. Black polystyrene 96-well microplates (Nunc, Denmark) were used. AAPH, Trolox and fluorescein solutions were diluted in $75 \mathrm{mM}$ phosphate buffer (pH 7.4). Trolox was used as a standard, and a blank control was performed using a sample solvent for all the methods. All values of antioxidant activity were performed in triplicate and expressed in $\mu \mathrm{M}$ Trolox-equivalents (TE)/g DW.

\subsection{Energy Potential}

The higher heating values (HHVs) of crude olive pomace, liquid and pulp fraction samples were measured by an automatic adiabatic bomb calorimeter (Parr calorimeter Type 6200). Measurements were made in duplicate (1 g of sample) according to EN 14918 and following Reference [34]. The samples of crude olive pomace and its pulp fraction were compacted in pellets before analysis, to prevent the occurrence of uncontrolled combustion. The interior surface of the bomb was washed with distilled water and collected in a beaker. The bomb washings were titrated with a standard sodium carbonate solution $(0.0709 \mathrm{~N})$. The $\mathrm{pH}$ and moisture content of stones fraction samples were evaluated to validate their quality as solid biofuel.

\subsection{Evaluation of the Potential Valorisation of Olive Pomace Using the Fractionation Approach in the Centre} Region of Portugal: Case Study

To illustrate the potential of the proposed approach, a case study was evaluated considering the situation in the centre region of Portugal (third major olive oil producer region in Portugal), which represented around 15\% of the national olive oil production in 2018 using the data from Instituto Nacional de Estatística (INE) [35].

\subsection{Statistical Analysis}

Data obtained for all parameters were analysed using a one-way analysis of variance (ANOVA). Tukey's post hoc test was applied for comparison of means, and differences were considered significant at $p<0.05$. The Shapiro-Wilk test confirmed the normality of data distribution. Statistical analyses were carried out using R Software.

\section{Results and Discussion}

\subsection{Fractionation Approach}

The wet and dry fractionation applied to crude olive pomace samples from OM 1, and OM 2 was shown to be reproducible. The yield (\% DW) for the different fractions was similar for both crude olive pomace samples. Figure 1 presents the proposed process for "zero waste" valorisation of olive pomace, including the principal mass balances. The first step of wet fractionation (centrifugation) led to two different fractions: sediment and supernatant. The sediment (solid fraction) was the most representative fraction for both crude olive pomace samples (63-53\% of crude olive pomace fresh weight). As a result of this first fractionation, the moisture and sugar concentration of solid fraction were reduced, facilitating its drying, and the crude olive pomace phenolics were recovered mainly in the liquid fraction (supernatant) [18]. In the present approach, the wet fractionation (centrifugation) 
followed by freeze-drying allowed to obtain 0.02 to $0.03 \mathrm{~kg}$ of liquid fraction from $1 \mathrm{~kg}$ of the wet olive pomace, showing a yield of $9 \%(\mathrm{DW})$ for both crude olive pomace samples analysed. A higher water loss occurred during the drying of liquid and solid fraction from OM 2 due to their higher moisture (liquid fraction: $95.29 \pm 0.81$, solid fraction: $68.18 \pm 1.86$ ) than the liquid and solid fraction obtained from OM1 (liquid fraction: $88.64 \pm 0.36$, solid fraction: $62.07 \pm 0.08$ ).

After the drying step and dry fractionation (milling and sieving), two different fractions were obtained, the stones and pulp fraction. For both crude olive pomace samples $(0.16-0.23 \mathrm{~kg}$ from $1 \mathrm{~kg}$ of wet olive pomace), pulp fraction had the highest yield ( $\%$ DW) around $65 \%$ and $71 \%$ for the OM 1 and OM 2 samples, respectively. On the other hand, a yield ( $\%$ DW) between $20 \%$ and $26 \%$ was attained for the stones fraction.

Other fractionation approaches have been applied to olive pomace [17,18]. Delisi et al. [18] obtained an extract rich in phenolic compounds and olive pomace oil from the liquid fraction and a solid biofuel from the solid fraction. The simple conversion of the solid fraction in solid biofuel neglected not only the high value of the compounds like fibre and phenolics presented in this fraction but also compromised its performance as a solid biofuel due to the risk of occurrence of uncontrolled combustion triggered by the presence of fat and small particles [12]. On the other hand, Ying et al. [17] ignored the energy potential of the stones fraction completely, using a considerable amount of water prior to centrifugation and discarded a considerable amount of olive pomace pulp fraction (not using a dry fractionation step to separate the pulp from stones). Neither of these two studies reported the yields of each of the fractions obtained from olive pomace fractionation. Besides that, the approaches reported in the literature have not explored the whole olive pomace fractions' potential, compromising not only the quality of the added-value products but also the "zero waste" goal. In contrast, the fractionation approach proposed in this work appears to be a promising and sustainable alternative to create different added-value products from olive pomace biomass without any consumption of water nor chemicals, and firstly, prioritising higher value applications and lastly, the energy valorisation according to circular bioeconomy principles [36].

\subsection{Proximate Composition}

The proximate composition of crude olive pomace, liquid and pulp fraction samples is presented in Table 1. The liquid (2.67-2.73 g/100 g DW) and pulp fraction (0.30-0.99 g/100 g DW) exhibited lower moisture content. When comparing the liquid and pulp fraction, the liquid fraction was shown to contain a higher amount of carbohydrates (73.34-77.17 g/100 g DW) and ashes (11.27-10.74 g/100 g DW). An equivalent amount of carbohydrates $(82.4 \%$ DW) were obtained by Ying et al. [17] for their liquid fraction, however, they reported a lower ash content (3.5\%) that could result from the non-environmental addition of water [37]. On the other hand, pulp fraction was characterised by the inherent fibre richness of crude olive pomace [38], exhibiting a high crude fibre content (54-55\% DW). Ying et al. [17] reported lower fibre content in their flesh-enriched fraction $(42.7 \% \mathrm{DW})$, probably because of the discharge of a substantial amount of pulp together with stones and the water addition (extraction of soluble fibres to supernatant). Besides that, the pulp fraction exhibited a significant amount of protein (8-9\% DW) and fat $(15-21 \%$ DW). The significant differences in fat and ash composition of the pulp fractions obtained from OM 1 and OM 2 could be explained by differences in olive varieties and maturation degree [39]. Comparing the proximate composition from the liquid and pulp fraction samples obtained from the two crude olive pomace samples used (OM 1 and OM 2), a similar composition was attained.

\subsection{Detergent Fibre}

The study of the detergent fibre composition of crude olive pomace, liquid and pulp fraction samples is presented in Table 1. Neutral detergent fibre is a good predictor of the nutritional value of dietary fibre [40], especially in insoluble fibre-rich samples like olive pomace [3]. In the liquid fraction, the neutral detergent fibre content was defined as "not detected", due to the limitation of the neutral detergent fibre method regarding water-soluble fibre measurement. Despite this limitation of the 
method, pulp fraction exhibited a high amount of neutral detergent fibre (53-59\% DW) close to the value of crude fibre reported above and higher than the total dietary fibre reported by Ying et al. [17] to their flesh-enriched fraction $(42.7 \% \mathrm{DW})$. This high content of neutral detergent fibre reported for the pulp fraction in this study supports its potential application in food formulation as a source of fibre. Fibre fortification is increasing due to its well-known health-promoting properties [19].

Table 1. Chemical composition of crude olive pomace (C-OP) and edible olive pomace fractions (L-OP and P-OP) produced after the wet and dry fractionation processes ( $\mathrm{g} / 100 \mathrm{~g}$ DW (dry weight)).

\begin{tabular}{|c|c|c|c|c|c|c|c|}
\hline \multirow{2}{*}{\multicolumn{2}{|c|}{ Chemical Components }} & \multicolumn{2}{|c|}{ C-OP } & \multicolumn{2}{|c|}{ L-OP } & \multicolumn{2}{|c|}{ P-OP } \\
\hline & & OM 1 & OM 2 & OM 1 & OM 2 & OM 1 & OM 2 \\
\hline \multirow{6}{*}{$\begin{array}{l}\text { Proximate } \\
\text { Compostion } \\
(\mathrm{g} / 100 \mathrm{~g} \text { DW) }\end{array}$} & Moisture & $0.93 \pm 0.01^{b}$ & $0.98 \pm 0.07^{b}$ & $2.66 \pm 0.31^{\mathrm{a}}$ & $2.94 \pm 0.01^{\mathrm{a}}$ & $0.63 \pm 0.04^{b}$ & $0.91 \pm 0.04^{b}$ \\
\hline & Ash & $4.48 \pm 0.09^{c}$ & $4.93 \pm 0.09^{\mathrm{d}}$ & $10.74 \pm 0.21^{b}$ & $11.27 \pm 0.18^{\mathrm{a}}$ & $3.11 \pm 0.19^{\mathrm{e}}$ & $1.97 \pm 0.03^{\mathrm{f}}$ \\
\hline & Crude Fibre & $35.90 \pm 1.32^{b}$ & $31.94 \pm 1.44^{b}$ & $0.13 \pm 0.10^{c}$ & $0.09 \pm 0.01^{c}$ & $54.54 \pm 2.63^{a}$ & $54.08 \pm 2.06^{a}$ \\
\hline & Protein & $8.75 \pm 0.13^{\mathrm{a}}$ & $8.82 \pm 0.15^{\mathrm{a}}$ & $3.80 \pm 0.24 \mathrm{~d}$ & $4.41 \pm 0.12^{c}$ & $7.98 \pm 0.18^{b}$ & $8.71 \pm 0.12^{\mathrm{a}}$ \\
\hline & Fat & $15.61 \pm 1.37^{b}$ & $20.04 \pm 0.58^{\mathrm{a}}$ & $2.68 \pm 0.29^{\mathrm{d}}$ & $5.56 \pm 0.50^{c}$ & $14.99 \pm 0.41^{b}$ & $21.34 \pm 0.94^{\mathrm{a}}$ \\
\hline & Carbohydrates & $33.28 \pm 2.37^{b}$ & $32.31 \pm 1.29^{b}$ & $77.17 \pm 0.88^{a}$ & $73.34 \pm 1.12^{\mathrm{a}}$ & $18.77 \pm 2.87^{c}$ & $11.92 \pm 1.89^{d}$ \\
\hline \multirow{2}{*}{$\begin{array}{c}\text { Detergent Fibre } \\
\text { (g/100 g DW) }\end{array}$} & NDF & $46.48 \pm 1.47^{\mathrm{b}, \mathrm{c}}$ & $40.76 \pm 2.76^{c}$ & ND & ND & $53.29 \pm 0.46^{\mathrm{a}, \mathrm{b}}$ & $59.28 \pm 1.98^{a}$ \\
\hline & $\mathrm{ADF}$ & $31.06 \pm 0.73^{b}$ & $25.34 \pm 0.95^{c}$ & ND & ND & $33.51 \pm 0.88^{\mathrm{a}, \mathrm{b}}$ & $36.66 \pm 0.62^{\mathrm{a}}$ \\
\hline \multirow{9}{*}{$\begin{array}{c}\text { Structural } \\
\text { Carbohydrates } \\
(\mathrm{g} / 100 \mathrm{~g} \text { DW) }\end{array}$} & Cellulose (as glucose) & $9.55 \pm 0.38^{a, b}$ & $8.60 \pm 0.54^{b}$ & ND & ND & $10.90 \pm 1.26^{\mathrm{a}}$ & $10.32 \pm 0.68^{\mathrm{a}, \mathrm{b}}$ \\
\hline & Hemicellulose & $11.29 \pm 0.50^{\mathrm{a}, \mathrm{b}}$ & $10.28 \pm 0.25^{b}$ & ND & ND & $11.85 \pm 0.72^{\mathrm{a}}$ & $12.40 \pm 0.94^{\mathrm{a}}$ \\
\hline & Xylose & $8.03 \pm 0.26^{b}$ & $6.50 \pm 0.21^{b}$ & ND & ND & $8.07 \pm 0.51^{\mathrm{a}}$ & $8.35 \pm 0.69^{a}$ \\
\hline & Arabinose & $0.36 \pm 0.13^{b}$ & $0.83 \pm 0.13^{a}$ & ND & ND & $0.61 \pm 0.11^{\mathrm{a}, \mathrm{b}}$ & $1.70 \pm 0.06^{\mathrm{a}}$ \\
\hline & Mannose & $1.02 \pm 0.32^{\mathrm{a}}$ & $1.06 \pm 0.20^{\mathrm{a}}$ & ND & ND & $1.05 \pm 0.15^{\mathrm{a}}$ & $1.26 \pm 0.21^{\mathrm{a}}$ \\
\hline & Galactose & $1.88 \pm 0.05^{\mathrm{a}}$ & $1.79 \pm 0.05^{b}$ & ND & ND & $2.12 \pm 0.03^{a}$ & $2.07 \pm 0.01^{\mathrm{a}}$ \\
\hline & Lignin & $43.95 \pm 1.31^{\mathrm{a}}$ & $42.48 \pm 0.56^{\mathrm{a}}$ & ND & ND & $43.38 \pm 0.32^{\mathrm{a}}$ & $45.72 \pm 1.76^{a}$ \\
\hline & Insoluble & $26.84 \pm 0.76^{\mathrm{a}}$ & $25.06 \pm 1.69^{\mathrm{a}}$ & ND & ND & $23.62 \pm 0.94^{\mathrm{a}}$ & $26.49 \pm 1.53^{\mathrm{a}}$ \\
\hline & Soluble & $17.12 \pm 0.76^{\mathrm{a}}$ & $17.42 \pm 1.21^{\mathrm{a}}$ & ND & ND & $19.76 \pm 0.63^{a}$ & $19.23 \pm 0.24^{\mathrm{a}}$ \\
\hline \multirow{4}{*}{$\begin{array}{c}\text { Pectins } \\
\text { (g GUAE/100 g } \\
\text { DW) }\end{array}$} & TSP & $3.23 \pm 0.50^{a}$ & $2.92 \pm 0.24^{a}$ & $0.69 \pm 0.28^{b}$ & $1.33 \pm 0.16^{b}$ & $3.37 \pm 0.90^{\mathrm{a}}$ & $2.64 \pm 0.15^{\mathrm{a}}$ \\
\hline & WSP & $0.64 \pm 0.22^{\mathrm{d}, \mathrm{e}}$ & $1.00 \pm 0.16^{b}$ & $0.77 \pm 0.12^{b, c}$ & $1.32 \pm 0.16^{\mathrm{a}}$ & $0.49 \pm 0.08^{c, d}$ & $0.46 \pm 0.16^{\mathrm{d}}$ \\
\hline & CSP & $2.50 \pm 0.34^{a, b}$ & $1.86 \pm 0.26^{b}$ & ND & ND & $2.86 \pm 0.81^{\mathrm{a}}$ & $2.12 \pm 0.10^{\mathrm{a}, \mathrm{b}}$ \\
\hline & HSP & $0.09 \pm 0.04^{\mathrm{a}}$ & $0.17 \pm 0.10^{\mathrm{a}}$ & ND & ND & $0.02 \pm 0.01^{\mathrm{a}}$ & $0.06 \pm 0.01$ \\
\hline \multirow{3}{*}{$\begin{array}{c}\text { Soluble } \\
\text { Sugars } \\
(\mathrm{g} / 100 \mathrm{~g} \mathrm{DW})\end{array}$} & Total soluble sugars ${ }^{* 1}$ & $6.56 \pm 0.36^{\mathrm{e}}$ & $9.36 \pm 0.48^{c}$ & $19.01 \pm 3.74^{b}$ & $28.78 \pm 3.40^{\mathrm{d}}$ & $2.36 \pm 0.25^{c}$ & $4.41 \pm 0.16^{\mathrm{c}}$ \\
\hline & Glucose & $6.85 \pm 1.42^{b}$ & $6.31 \pm 0.61^{b, c}$ & $19.75 \pm 2.00^{c}$ & $20.37 \pm 1.74^{c}$ & $4.00 \pm 0.90^{b, c}$ & $2.67 \pm 0.61^{\mathrm{c}}$ \\
\hline & Mannitol & $7.16 \pm 1.40^{c, d}$ & $10.55 \pm 1.66^{c}$ & $21.10 \pm 2.55^{c}$ & $32.37 \pm 2.65^{b}$ & $4.81 \pm 1.61^{\mathrm{c}}$ & $4.08 \pm 0.88^{\mathrm{d}}$ \\
\hline
\end{tabular}

\subsection{Cellulose, Hemicellulose and Lignin}

As validated by the crude fibre and the neutral detergent fibre method, fibre is the most abundant component in crude olive pomace and pulp fraction. Polymerised sugars compose fibre into cellulose and hemicellulose structures, which can be quantified by HPLC after acid hydrolysis. The cellulose and hemicellulose content of crude olive pomace samples were not significantly different $(p<0.05)$. Hemicellulose (as the sum of xylose, arabinose, galactose and mannose) was a little more abundant in the pulp fraction ( $12 \% \mathrm{DW})$ than cellulose $(10-11 \% \mathrm{DW})$, with xylose $(8 \% \mathrm{DW})$ being the main hemicellulose sugar, followed by galactose ( $2 \%$ ) (Table 1$)$. The pulp fraction richness in xylose makes its potential application in the food industry even more feasible. Xylans have unique properties, like the capacity of interaction with bile and cholesterol, activation of colon peristalsis and important technological properties [41].

Taking into consideration that the olive endocarp is mostly lignified [3], the lignin content is high in pulp fraction (42-46\%). Lignin is a macromolecule inert for colonic fermentation but can be able to release when linked to phenolic compounds with low molecular weight (bound phenolics) (e.g., vanillin and caffeic acid). These phenolic compounds can play an essential role in gut health due to their antioxidant properties, antimicrobial and immunological activity [42,43]. 


\subsection{Pectins Quantification}

Some studies have reported the extraction of pectins from olive by-products [44]. The extractable pectins of edible fractions (liquid and pulp fraction) were estimated (Table 1). The total extractable pectins were not significantly different in the crude olive pomace and pulp fraction samples $(p<0.05)$. Overall, the pulp fraction showed the highest total extractable pectins amount (2.64-3.37 g GUAE/100 g DW), and chelator-soluble pectins were the most significant, corresponding to $64-85 \%$ of total extractable pectins. On the other hand, in the liquid fraction, only water-soluble pectins were detected (0.77-1.32 $\mathrm{g}$ GUAE/100 $\mathrm{g}$ DW) and in a higher amount than in the pulp fraction (0.46-0.49 $\mathrm{g}$ GUAE/100 $\mathrm{g}$ DW). Only a small amount of hydroxide-soluble pectins was detected in the pulp fraction. In conclusion, the total extractable pectins were concentrated in the pulp fraction, but the water-soluble pectins were condensed in the liquid fraction from olive pomace. Soluble pectins identified in the liquid fraction were also known to have a positive effect on decreasing blood glucose [10].

\subsection{Soluble Sugars}

Total soluble sugar content (using glucose as standard) was not significantly different between samples of crude olive pomace and respective fractions, except for the liquid fraction $(p<0.05)$ (Table 1$)$. The HPLC analysis of soluble sugars allowed the identification of glucose and mannitol (Table 1), revealing the higher concentration of mannitol in agreement with previously reported results for maturated olive fruits [45]. The liquid fraction revealed significantly different amounts of mannitol between samples (OM 1 and OM 2). The higher concentration of mannitol in the liquid fraction from OM $2(32.37 \pm 2.65 \mathrm{~g} / 100 \mathrm{~g}$ DW) than OM $1(21.10 \pm 2.55 \mathrm{~g} / 100 \mathrm{~g}$ DW) can be explained by the higher fat content and a possibly higher degree of maturation of its olives. During olive maturation, it is normal to occur an increase of mannitol at the same time as olive mesocarp accumulates oil [39].

In general, the designed fractionation approach led to a concentration of the soluble sugars in the liquid fraction, principally mannitol (4-8 times higher than in the pulp fraction), as reported previously [18]. So, in terms of nutritional composition, the liquid fraction was mostly a source of minerals and carbohydrates (glucose and mannitol). This composition can be an asset as a functional component to formulate sport food products [46] or food products with health benefits, namely, to decrease the intake of carbohydrates that raise blood glucose levels [47]. Mannitol as the predominant soluble sugar in the liquid fraction is a non-metabolisable (uptake insulin-independent) and low-energy sweetener $(1.6 \mathrm{kcal} / \mathrm{g}$ ), but also a food preservative (as an antioxidant and as a reducer of the sugar crystallisation) [48].

\subsection{Infrared Spectroscopy}

The major peak assignments in olive pomace fractions measured by FTIR include lipids, polysaccharides and pectin and cellulose components (Figure 2). Unsaturated fatty acids (like linoleic and oleic acid) and triacylglycerols were identified at $3008 \mathrm{~cm}^{-1}$ (C-H stretching of olefinic double bonds) and $1744 \mathrm{~cm}^{-1}$ (ester peak because of $\mathrm{C}=\mathrm{O}$ stretching vibration of carbonyl groups of the triacylglycerols), respectively [49]. In agreement with the more abundant lipid content of the pulp fraction, larger peak areas were detected at 2922 and $2850 \mathrm{~cm}^{-1}$ in the pulp fraction (methylene absorbance peaks associated with antisymmetric and symmetric stretching vibrations of aliphatic $\mathrm{C}-\mathrm{H}$ in $\mathrm{H} 2$ and terminal $\mathrm{CH} 3$ groups, respectively) [49].

The bands at 3300-3400 (vibration of hydrogens in bound $\mathrm{OH}$ groups of the type alcohol or phenol) and $2922 \mathrm{~cm}^{-1}$ (C-H stretching vibrations of asymmetric aliphatic structures) could be attributed to high levels of less condensed structures, such as phenolic compounds and acids [49]. These bands were more evident in liquid than in pulp fraction. 


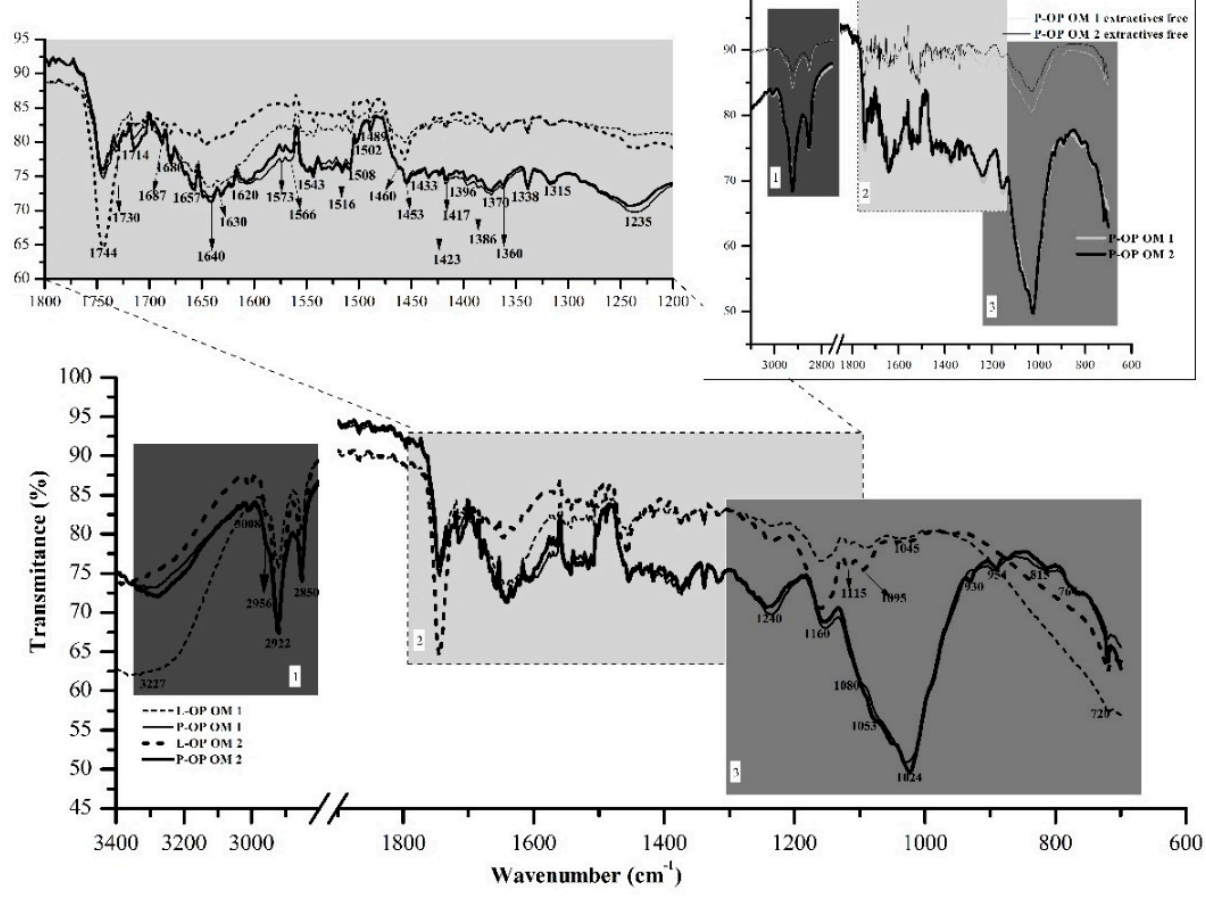

Figure 2. FTIR spectra of the liquid-rich fraction (L-OP) and pulp-rich fraction (P-OP) produced after the wet and dry fractionation process of crude olive pomace (C-OP). Abbreviations: $\mathrm{C}-\mathrm{OP}-$ crude olive pomace, L-OP-liquid-rich fraction, $\mathrm{P}-\mathrm{OP}$ - pulp-rich fraction.

The vibration peaks of cellulose and lignin were more evident in pulp fraction, at wavelengths ranging between 1315 and $1460 \mathrm{~cm}^{-1}\left(1370 \mathrm{~cm}^{-1}, \mathrm{CH}_{2}\right.$ bending mode (xyloglucan, cellulose), $1338 \mathrm{~cm}^{-1}$, $\mathrm{CH}$ deformation from ring vibration (polysaccharides, pectin and cellulose)). At 1080 and $1024 \mathrm{~cm}^{-1}$, two significant peaks in the pulp fraction were identified, which are typical from xyloglucans (C-O stretching and C-C stretching) and C-O stretching and C-C stretching (pectin, cellulose). Pectin was noticed mainly in peaks between 1100 and $1600 \mathrm{~cm}^{-1}$ (namely $1630 \mathrm{~cm}^{-1}, \mathrm{COO}^{-}$asymmetric stretching (pectin ester group), $1240 \mathrm{~cm}^{-1}, \mathrm{C}-\mathrm{O}$ stretching (pectin), $1160 \mathrm{~cm}^{-1} \mathrm{O}-\mathrm{C}-\mathrm{O}$ symmetric stretching (glycosidic link of cellulose, pectin)). The presence of soluble sugars was identified between 1045 and $1160 \mathrm{~cm}^{-1}$ in the liquid fraction.

The differences in peak intensity and some shifts in peak position between the liquid and pulp fractions were related to the content, type and structure of its components. The principal spectral variations among the liquid and pulp fraction were principally due to higher fat content and fibre richness (lignin and xylans composition) of the pulp fraction versus the higher phenolic and sugar content of the liquid fraction obtained from olive pomace. The FTIR results allowed to deduce that the pulp fraction could not only be explored as a source of fibre but also of unsaturated fatty acids in food formulation for its beneficial effects on the reduction of cholesterol and triglycerides [50].

Assignments were based on studies from previous work on the FTIR analysis of olive pomace [1], olive mill wastewater [51], olive pomace fractions [17] and olive oil [49].

\subsection{Bioactivity Characterisation}

\subsubsection{Total Phenolic Content and Antioxidant Activity of Free and Bound Phenolics}

The TPC and antioxidant activity (DPPH, ABTS and ORAC) of crude olive pomace, liquid and pulp fraction samples are presented in Figure 3. Total TPC resulted from the sum of the free phenolic compounds with the bound phenolic compounds. TPC in the crude olive pomace samples was of 
22.73-24.51 mg GAE/g DW in crude olive pomace without significant differences between each other $(p>0.05)$ regarding TPC from free and bound phenolic compounds. Different TPC results were reported in previous works for crude olive pomace: higher [38] and lower values [20], mainly due to the differences between olive cultivars and oil extraction conditions.

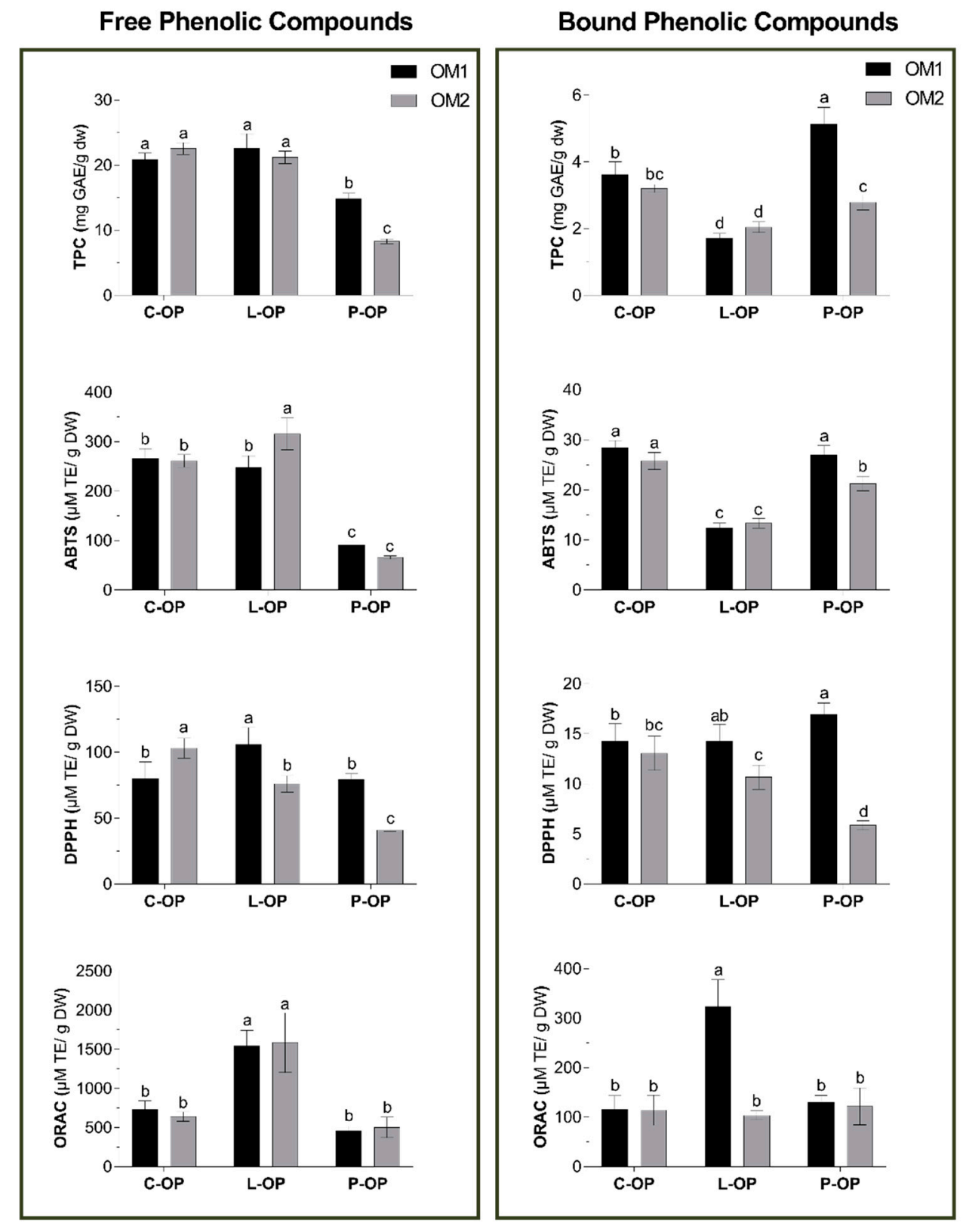

Figure 3. Content of total, free and bound phenolic compounds and antioxidant activity using DPPH, ABTS and ORAC methods from crude olive pomace (C-OP), the liquid-rich fraction (L-OP) and pulp-rich fraction from olive pomace (P-OP). Data were expressed as mean \pm SD $(n=3)$. The different superscripts in the same column were significantly different $(p<0.05)$. Abbreviations: OM 1 -olive mill 1, OM 2-olive mill 2, C-OP-crude olive pomace, L-OP-liquid-rich fraction, P-OP-pulp-rich fraction. GAE-Gallic acid equivalents, TE-Trolox equivalents. 
Liquid fraction (21.21-22.67 mg GAE/g DW) and crude olive pomace exhibited similar values of TPC regarding free phenolic extracts, and pulp fraction (8.32-14.86 mg GAE/g DW) revealed significantly lower values $(p<0.05)$. On the other hand, TPC of bound phenolic extracts from pulp fraction (2.78-5.13 mg GAE/g DW) was similar or higher than in crude olive pomace samples (3.20-3.62 mg GAE/g DW). However, as expected, higher recovery of phenolic compounds was achieved in liquid rather than in pulp fraction.

Antioxidant activity of crude olive pomace and edible fractions (liquid and pulp fraction) were evaluated using three different methods (DPPH, ABTS and ORAC), due to the absence of a single antioxidant determination methodology able to reflect the total antioxidant activity of a sample. The model of scavenging stable radicals, DPPH, is widely used to evaluate antioxidant capacities of natural products, including olive oil samples [52]. The DPPH method showed that the proton-removal activity of free phenolic compounds from the liquid fraction (76.03-106.03 $\mu \mathrm{M} \mathrm{TE} / \mathrm{g} \mathrm{DW})$ was higher than pulp fraction (41.05-79.20 $\mu \mathrm{M}$ TE/g DW) and analogous to crude olive pomace (79.94-103.15 $\mu \mathrm{M}$ TE/g DW). ABTS showed the same tendency as DPPH, where free phenolic compounds' extract of the liquid fraction showed higher values of antioxidant activity and similar to crude olive pomace. Nonetheless, the bound phenolic extracts of the pulp fraction had the double capacity $(21.25-26.98 \mu \mathrm{M}$ $\mathrm{TE} / \mathrm{g} \mathrm{DW})$ to inhibit the free radicals when compared to the liquid fraction (12.34-13.34 $\mu \mathrm{M} \mathrm{TE} / \mathrm{g} \mathrm{DW})$ $(p<0.05)$. When comparing ABTS with DPPH, ABTS had higher values, which could be related to the use of methanol in both methods. Water is commonly used as a solvent in ABTS, and its substitution by methanol allows to improve the evaluation of the total antioxidant activity of complex samples (aqueous and organic compounds) [33].

In ORAC, the liquid fraction (1546.93-1585.46 $\mu \mathrm{M}$ TE/g DW) also showed the highest antioxidant activity value compared to the pulp fraction (454.74-502.80 $\mu \mathrm{M} \mathrm{TE} / \mathrm{g} \mathrm{DW})$ or crude olive pomace (641.05-734.81 $\mu \mathrm{M}$ TE/g DW) $(p<0.05)$. The ORAC values were much higher than the values obtained by DPPH and ABTS. Similar differences were reported in antioxidant activity assays of olives [53] and olive pomace [38]. These differences probably arise from the different mechanisms involved during each methodology: single-electron transfer in the case of DPPH/ABTS and hydrogen atom transfer in the case of the ORAC assay.

The values of the three methodologies are in agreement with the TPC results, showing that the phenolic compounds are the main antioxidant activity contributor of liquid and pulp fraction. All three antioxidant activity methods applied indicate a stronger antioxidant activity $(p<0.05)$ of the liquid fraction, but the antioxidant activity of the pulp fraction along with its higher fibre content is by the established concept of an "antioxidant dietary fibre" material [19].

\subsubsection{Identification of Phenolic Compounds}

A detailed analysis of free and bound phenolic compounds is required to elucidate which compounds are responsible for the antioxidant activity of the edible fractions (liquid and pulp fractions). Table 2 shows the free phenolic and bound phenolic profile of the crude olive pomace, liquid and pulp fractions, identified by LC-ESI-UHR-QqTOF-MS. The distribution (in percentage) of the phenolic compounds from C-OP, L-OP and P-OP are given in the Supplementary Material (Figure S1). 
Table 2. Phenolic compounds identified (or tentatively identified) in free (FPC) and bound phenolic (BPC) extract crude olive pomace (C-OP) and edible olive pomace fractions (L-OP and P-OP) produced after the wet and dry fractionation process.

\begin{tabular}{|c|c|c|c|c|c|c|c|c|c|c|c|}
\hline Phenolic Compound & FPC & ВPC & $\begin{array}{c}\text { RT } \\
(\mathrm{min})\end{array}$ & $\begin{array}{c}\text { UV-Vis } \\
\max \end{array}$ & Formula & $\mathrm{m} / \mathrm{z} \exp$ & $\mathrm{m} / \mathrm{z}$ theo & $\begin{array}{l}\text { Error } \\
(\mathrm{mDa})\end{array}$ & mSigma & Fragments & Ref. \\
\hline \multicolumn{12}{|c|}{ Hydroxytyrosol and tyrosol derivatives } \\
\hline Dihydroxytyrosol & $\boldsymbol{v}$ & $\checkmark$ & 1.9 & 279 & $\mathrm{C}_{8} \mathrm{H}_{10} \mathrm{O}_{4}$ & 169.0504 & 169.0506 & 0.3 & 5.1 & $151.0397 ; 123.0448$ & [54] \\
\hline Hydroxytyrosol glucoside & $\checkmark$ & $\boldsymbol{v}$ & 3.9 & 278 & $\mathrm{C}_{14} \mathrm{H}_{20} \mathrm{O}_{8}$ & 315.1092 & 315.1088 & -0.4 & 16.3 & $315.1090 ; 153.0555 ; 123.0450$ & [55] \\
\hline Hydroxytyrosol & $\checkmark$ & $\checkmark$ & 4.3 & 281 & $\mathrm{C}_{8} \mathrm{H}_{10} \mathrm{O}_{3}$ & 153.0557 & 153.0555 & -0.2 & 0.9 & $153.0554 ; 123.0450$ & (a) \\
\hline Tyrosol glucoside & $\checkmark$ & $\boldsymbol{*}$ & 8.3 & 275 & $\mathrm{C}_{14} \mathrm{H}_{20} \mathrm{O}_{7}$ & 299.1144 & 299.1136 & -0.2 & 15.1 & $299.1139 ; 119.0349 ; 101.0244,89.0245$ & [55] \\
\hline Tyrosol & $\checkmark$ & $\boldsymbol{x}$ & 12 & 276 & $\mathrm{C}_{8} \mathrm{H}_{10} \mathrm{O}_{2}$ & 137.0609 & 137.0608 & 0.5 & n.a. & 137.0603; 111.0084; 95.0510 & (a) \\
\hline \multicolumn{12}{|c|}{ Secoiridoids and Derivatives } \\
\hline Oleoside & $\boldsymbol{v}$ & $\checkmark$ & 6.2 & 270 & $\mathrm{C}_{16} \mathrm{H}_{22} \mathrm{O}_{11}$ & 389.1092 & 389.1089 & -0.3 & 5.6 & $389.1088 ; 183.0664 ; 165.0560 ; 121.0656 ; 345.1195$ & [55] \\
\hline Verbascoside & $\checkmark$ & $\boldsymbol{*}$ & 13.3 & 330 & $\mathrm{C}_{29} \mathrm{H}_{36} \mathrm{O}_{15}$ & 623.1990 & 623.1981 & -0.9 & 8.3 & $623.1983 ; 161.0244 ; 461.1665 ; 162.0276 ; 135.0451$ & [55] \\
\hline Caffeoyl-6'-secologanoside & $\checkmark$ & $\boldsymbol{*}$ & 14.7 & 326 & $\mathrm{C}_{25} \mathrm{H}_{28} \mathrm{O}_{14}$ & 551.1416 & 551.1406 & 0 & 18.1 & $551.1416 ; 507.1504 ; 345.1193 ; 281.0673 ; 161.0245$ & [55] \\
\hline Oleuropein & $\checkmark$ & $\boldsymbol{*}$ & 17.1 & 280 & $\mathrm{C}_{25} \mathrm{H}_{32} \mathrm{O}_{13}$ & 539.1761 & 539.1771 & 0.7 & 27.6 & $539.1764 ; 307.0828 ; 275.0931 ; 223.0613 ; 179.0566$ & (a) \\
\hline Comselogoside & $\checkmark$ & $\boldsymbol{*}$ & 17.5 & 311 & $\mathrm{C}_{25} \mathrm{H}_{28} \mathrm{O}_{13}$ & 535.1462 & 535.1457 & -0.1 & 19.9 & $535.1465 ; 145.0296 ; 491.1558 ; 389.1093 ; 345.1197$ & [55] \\
\hline \multicolumn{12}{|c|}{ Flavonoids } \\
\hline Rutin & $\boldsymbol{v}$ & $\boldsymbol{v}$ & 10.7 & 355 & $\mathrm{C}_{27} \mathrm{H}_{30} \mathrm{O}_{16}$ & 609.1465 & 609.1461 & -0.1 & 18 & $609.1462 ; 300.0289$ & (a) \\
\hline Luteolin-7-O-glucoside & $\checkmark$ & $\checkmark$ & 11.6 & 349 & $\mathrm{C}_{21} \mathrm{H}_{20} \mathrm{O}_{11}$ & 447.0929 & 447.0933 & 0.8 & 20.5 & $447.0925 ; 285.0414$ & (a) \\
\hline Luteolin & $\checkmark$ & $\boldsymbol{*}$ & 20.4 & 349 & $\mathrm{C}_{15} \mathrm{H}_{10} \mathrm{O}_{6}$ & 285.0414 & 285.0405 & -1 & 3.3 & $285.0414 ; 151.0037$ & (a) \\
\hline Quercetin & $\checkmark$ & $\boldsymbol{*}$ & 20.5 & 342 & $\mathrm{C}_{15} \mathrm{H}_{10} \mathrm{O}_{7}$ & 301.0362 & 301.0354 & -0.5 & 4.5 & $301.0359 ; 151.0035 ; 178.9988 ; 121.0294$ & (a) \\
\hline Apigenin & $\checkmark$ & $\boldsymbol{*}$ & 25.0 & 339 & $\mathrm{C}_{15} \mathrm{H}_{10} \mathrm{O}_{5}$ & 269.0461 & 269.0455 & -0.5 & 4.8 & $269.0461 ; 151.0035$ & (a) \\
\hline \multicolumn{12}{|c|}{ Phenolic Acids } \\
\hline Vanillin & $\boldsymbol{*}$ & $\boldsymbol{v}$ & 4.2 & 279 & $\mathrm{C}_{8} \mathrm{H}_{8} \mathrm{O}_{3}$ & 151.0400 & 151.0401 & 0.3 & 18.7 & $151.0397 ; 137.0235 ; 109.0290 ; 105.0341$ & (a) \\
\hline Hydroxybenzoic acid & $\boldsymbol{x}$ & $\checkmark$ & 5.6 & & $\mathrm{C}_{7} \mathrm{H}_{6} \mathrm{O}_{3}$ & 137.0241 & 137.0244 & 0.4 & 4 & $137.0241 ; 138.0280$ & [54] \\
\hline Caffeic acid-3-glucoside & $\checkmark$ & $\checkmark$ & 5.8 & 277 & $\mathrm{C}_{15} \mathrm{H}_{18} \mathrm{O}_{9}$ & 341.0876 & 341.0878 & 0.2 & 9.5 & $341.0876 ; 179.0351 ; 135.0450$ & [55] \\
\hline Caffeic acid & $\checkmark$ & $\checkmark$ & 7.0 & 323 & $\mathrm{C}_{9} \mathrm{H}_{8} \mathrm{O}_{4}$ & 179.0350 & 179.0350 & 0.0 & 7.5 & 179.0350; 135.0448 & (a) \\
\hline Coumaric acid & $\checkmark$ & $\checkmark$ & 9.0 & 309 & $\mathrm{C}_{9} \mathrm{H}_{8} \mathrm{O}_{3}$ & 163.0397 & 163.0401 & 0.3 & 19.6 & $163.0397 ; 119.0499$ & (a) \\
\hline Ferulic acid & $\boldsymbol{*}$ & $\checkmark$ & 10.4 & 323 & $\mathrm{C}_{10} \mathrm{H}_{10} \mathrm{O}_{4}$ & 193.0509 & 193.0506 & -0.3 & 18.6 & $193.0504 ; 178.0268 ; 134.0370$ & (a) \\
\hline
\end{tabular}

RT—retention time, $\boldsymbol{V}$-Compound identified, $\boldsymbol{x}$-Compound not identified, UV—ultraviolet, Error Ref-reference, (a) Comparison with standard, (b) Capriotti et al. [54] (c) Peralbo-Molina et al. [55]. 
The HPLC quantification of phenolic compounds for which a standard is available is presented in Table 3. In agreement with TPC results, the amounts of phenolic compounds identified in the free phenolic extract were higher than in the bound phenolic extract for all samples. The main phenolic classes identified in free phenolic extracts were (1) hydroxytyrosol/tyrosol and its derivatives, followed by (2) flavonoids class (largely luteolin), (3) comselogosid and derivatives class (essentially comselogoside, verbascoside and caffeoyl-6-secologanoside) and (4) phenolic acids (mainly caffeic acid and $p$-coumaric acid). The liquid fraction exhibits a rich composition in hydroxytyrosol and its derivatives (625.76 \pm 51.33 and $513.61 \pm 27.85 \mathrm{mg} / 100 \mathrm{~g}$ DW in OM 1 and OM2, respectively) owing to the hydrophilic nature of this phenolic class [56]. Previous works also supported the efficiency of centrifugation to recover these compounds [18]. Hydroxytyrosol and its derivatives are one of the principal phenolic compounds present in olive fruits and by-products. They have been characterised to have potent biological activities as an antioxidant, anti-inflammatory and antimicrobial, with promising applications in foods, but also in cosmetics and medicine [5,8,57].

Moreover, the European Food Safety Authority (EFSA) has issued a favourable scientific opinion regarding health claims for the dietary consumption of hydroxytyrosol and its derivatives (protection of blood lipids from oxidative damage) [58]. As a result, in the last years, hydroxytyrosol application and recovery studies have increased exponentially. Comselogoside, verbascoside, caffeoyl-6-secologanoside and caffeic acid, which are also associated with the prevention of cardiovascular diseases, were also identified in a slightly higher amount in liquid than in pulp fraction.

Luteolin was the predominant phenolic compound of the pulp fraction. The reduced water solubility of luteolin could explain the retention of this compound in the pulp fraction [59]. Studies reported that luteolin has antioxidant, anti-microbial, anti-inflammatory and anti-diabetic activity [60]. The pulp fraction was also characterised by a significant amount of bound phenolic compounds, namely vanillin, hydroxytyrosol, protocatechuic acid and caffeic acid. These bound phenolic compounds represented a significant amount of the total phenolic compounds of the pulp fraction (18-27\%). The highest amount of bound phenolics in the pulp fraction could be linked to its higher fibre content and with the possible linkage of vanillin, caffeic and protocatechuic acids to structural components of the cell wall (cellulose, lignin and protein) [61]. Caffeic acid was detected in a much higher amount in bound form, and protocatechuic acid and vanillin were only noticed in bound form. Caffeic acid has been related to the reduction or complete inhibition of $\alpha$-glucosidase activity (potential anti-diabetic activity) [62]. Vanillin and protocatechuic acid have been described to have potent antioxidant activity and antimicrobial activity [63,64]. Other compounds like hydroxybenzoic and ferulic acid were only identified in bound phenolics extracts.

Overall, the liquid fraction allowed the recovery of a considerable amount of hydroxytyrosol and its derivatives related to the prevention of cardiovascular diseases, and the pulp fraction exhibited a significant quantity of free (mainly luteolin) and bound phenolics. Therefore, the liquid fraction could be explored by the food industry to achieve new food products with health benefits in the prevention of cardiovascular diseases. Daily consumption of less than $1 \mathrm{~g}$ of the liquid fraction would provide the amount of hydroxytyrosol $(5 \mathrm{mg})$ that would be needed to protect low-density lipoprotein (LDL) particles from oxidative damage, according to the health claim approved by the EFSA [58]. Besides the health benefits, the liquid fraction exhibited a more potent antioxidant activity, which supports its potential application as a food preservative (as an antioxidant and/or antimicrobial). On the other hand, the pulp fraction fibre, including the lignin, could act as a carrier of the bound phenolics [42] that could exert significant gut health benefits, including antioxidant and antibacterial activity able to repress pathogenic bacteria in the colon (i.e., Escherichia coli, Clostridium), but also prebiotic-like effects by stimulating the growth of beneficial bacteria (i.e., Lactobacillus and Bifidobacterium spp.) [65]. Besides that, the pulp fraction exhibited a significant amount of free phenolics (mainly luteolin and hydroxytyrosol) and significant antioxidant activity. So, the pulp fraction could be considered a significant source of "antioxidant dietary fibre", which can be applied as a food ingredient that offers the technological and gut health-promoting properties associated to fibre and antioxidants [19]. 
Table 3. Phenolic composition (mg/100 g DW) in crude olive pomace (C-OP), a liquid-rich fraction (L-OP) and pulp-rich fraction (P-OP) from olive pomace.

\begin{tabular}{|c|c|c|c|c|c|c|c|}
\hline \multirow{2}{*}{\multicolumn{2}{|c|}{$\begin{array}{l}\text { Phenolic } \\
\text { Compound }\end{array}$}} & \multicolumn{2}{|c|}{ C-OP } & \multicolumn{2}{|c|}{ L-OP } & \multicolumn{2}{|c|}{ P-OP } \\
\hline & & \multirow{3}{*}{$\begin{array}{c}\text { OM 1 } \\
207.08 \pm 13.95^{c} \\
17.35 \pm 6.03^{c}\end{array}$} & \multirow{3}{*}{$\begin{array}{c}\text { OM 2 } \\
173.67 \pm 13.68^{\mathrm{c}} \\
16.44 \pm 4.70^{\mathrm{c}}\end{array}$} & \multirow{3}{*}{$\begin{array}{c}\text { OM 1 } \\
573.43 \pm 59.62^{\mathrm{a}} \\
78.51 \pm 8.70^{\mathrm{a}}\end{array}$} & \multirow{3}{*}{$\begin{array}{c}\text { OM 2 } \\
504.73 \pm 27.67^{b} \\
15.99 \pm 1.53^{c}\end{array}$} & \multirow{3}{*}{$\begin{array}{c}\text { OM 1 } \\
81.62 \pm 20.98^{\mathrm{d}} \\
43.14 \pm 9.85^{\mathrm{b}}\end{array}$} & \multirow{3}{*}{$\begin{array}{c}\text { OM 2 } \\
26.54 \pm 8.35^{\mathrm{e}} \\
11.93 \pm 3.69^{\mathrm{c}}\end{array}$} \\
\hline & Free & & & & & & \\
\hline Hydroxytyrosol & Bound & & & & & & \\
\hline Tyrosol & Free & $51.21 \pm 3.01^{b}$ & $65.89 \pm 6.91^{\mathrm{a}}$ & ND & ND & $35.48 \pm 1.87^{c}$ & $20.75 \pm 3.48^{d}$ \\
\hline Protocatechuic acid & Bound & $10.30 \pm 1.17^{b}$ & $8.38 \pm 1.02^{b}$ & ND & ND & $15.73 \pm 1.32^{\mathrm{a}}$ & $10.09 \pm 1.03^{b}$ \\
\hline \multirow{2}{*}{ Caffeic acid } & Free & $21.92 \pm 1.71^{a}$ & $8.79 \pm 1.25^{c}$ & $23.63 \pm 3.10^{a}$ & $15.14 \pm 0.85^{b}$ & $14.01 \pm 0.58^{b}$ & $0.51 \pm 0.12^{\mathrm{d}}$ \\
\hline & Bound & $25.15 \pm 2.15^{b}$ & $16.61 \pm 3.25^{\mathrm{c}, \mathrm{d}}$ & $40.71 \pm 5.23^{\mathrm{a}}$ & $23.10 \pm 1.49^{b, c}$ & $34.76 \pm 3.48^{a}$ & $13.47 \pm 1.87^{\mathrm{d}}$ \\
\hline Vanillin & Bound & $1.39 \pm 0.23^{b}$ & $0.85 \pm 0.20^{c}$ & ND & ND & $1.63 \pm 0.18^{\mathrm{a}, \mathrm{b}}$ & $1.79 \pm 0.26^{\mathrm{a}}$ \\
\hline \multirow{2}{*}{ p-Coumaric acid } & Free & $7.41 \pm 0.58^{b}$ & $8.30 \pm 0.97^{b}$ & $8.04 \pm 1.17^{\mathrm{b}}$ & $15.75 \pm 1.80^{\mathrm{a}}$ & $6.46 \pm 0.16^{\mathrm{b}}$ & $1.40 \pm 0.13^{c}$ \\
\hline & Bound & $8.69 \pm 3.50^{\mathrm{d}}$ & $14.47 \pm 2.85^{\mathrm{b}}$ & $13.43 \pm 2.60^{b, c}$ & $19.47 \pm 0.45^{\mathrm{a}}$ & $9.64 \pm 0.64^{c, d}$ & $15.64 \pm 0.80^{\mathrm{a}, \mathrm{b}}$ \\
\hline Rutin & Free & ND & $30.85 \pm 2.71^{a}$ & ND & ND & ND & $16.49 \pm 0.93^{b}$ \\
\hline Luteolin-7-O-glucoside & Free & ND & $10.51 \pm 0.77^{\mathrm{a}}$ & ND & ND & ND & $10.31 \pm 1.09^{\mathrm{a}}$ \\
\hline Luteolin & Free & $18.40 \pm 0.51^{c}$ & $44.47 \pm 2.98^{\mathrm{a}}$ & ND & ND & $22.34 \pm 0.66^{b}$ & $45.26 \pm 1.47^{a}$ \\
\hline Quercitin & Free & $3.22 \pm 0.34^{\mathrm{a}, \mathrm{b}}$ & $3.45 \pm 0.46^{\mathrm{a}}$ & ND & ND & $2.80 \pm 0.36^{b}$ & $0.91 \pm 0.24^{c}$ \\
\hline \multirow{2}{*}{ Total } & Free & $\begin{array}{c}290.18 \pm 15.51^{\mathrm{c}} \\
77 \%\end{array}$ & $\begin{array}{c}346.03 \pm 24.37^{\mathrm{d}} \\
84 \%\end{array}$ & $\begin{array}{c}581.47 \pm 60.70^{\mathrm{a}} \\
84 \%\end{array}$ & $\begin{array}{c}520.47 \pm 29.17^{b} \\
92 \%\end{array}$ & $\begin{array}{c}152.45 \pm 22.0^{\mathrm{e}} \\
58 \%\end{array}$ & $\begin{array}{c}127.66 \pm 31.43^{\mathrm{e}} \\
72 \%\end{array}$ \\
\hline & Bound & $\begin{array}{c}62.87 \pm 8.26^{c} \\
17 \%\end{array}$ & $\begin{array}{c}56.75 \pm 10.99^{c} \\
13 \%\end{array}$ & $\begin{array}{c}132.64 \pm 0.93^{\mathrm{a}} \\
19 \%\end{array}$ & $\begin{array}{c}58.55 \pm 2.41^{c} \\
10 \%\end{array}$ & $\begin{array}{c}97.17 \pm 18.98^{b} \\
37 \%\end{array}$ & $\begin{array}{c}51.41 \pm 8.49^{c} \\
28 \%\end{array}$ \\
\hline
\end{tabular}

OM 1-Olive pomace from olive mill 1, OM 2-Olive pomace from olive mill 2, C-OP-Crude olive pomace, L-OP-liquid-rich fraction, $\mathrm{P}-\mathrm{OP}-$ pulp-rich fraction. ND-not detected by high-performance liquid chromatography (HPLC). Data were expressed as mean $\pm S D(n=3)$. The different superscripts in the same row were significantly different $(p<0.05)$.

\subsection{Energy Content}

The energy content obtained for samples following the fractionation ranged between 19 and $22 \mathrm{MJ} / \mathrm{kg}$ higher heating value (HHV) (Table 4). Crude olive pomace showed energy content equivalent to previous works [12]. The wet fractionation (pulp + stones fraction) did not reveal significant differences in HHV $(p<0.05)$ in comparison to crude olive pomace. However, the separation of the pulp fraction from the stones fraction significantly influenced the energy content values $(p<0.05)$. As expected, the pulp fraction exhibited the higher HHV ( 22 MJ/kg), due to its substantial oil content. However, the pulp fraction's high composition in oil and low weight could generate uncontrolled combustions and emissions disturbing the combustion and its performance as fuel [12]. The lowest HHV was shown in the stones fraction $(\sim 19 \mathrm{MJ} / \mathrm{kg})$. Nonetheless, these values were similar to those achieved in previous works focused on the stones fraction $(18.80 \mathrm{MJ} / \mathrm{kg})[66]$. Besides, the HHV obtained for the stones fractions were identical to other biomass sources, namely oak wood $(18.70 \mathrm{MJ} / \mathrm{kg})$ and pine bark (18.30 MJ/kg), and to most agricultural residues (e.g., vine shoots (18.30 MJ/kg), palm kernel $(18.67 \mathrm{MJ} / \mathrm{kg}))[67]$.

The moisture content of stones fraction samples showed a moisture content of $6 \%$ (OM 1: $5.48 \pm 0.01 \mathrm{~g} / 100 \mathrm{~g}$ DW, OM 2: $5.39 \pm 0.08 \mathrm{~g} / 100 \mathrm{~g} \mathrm{DW})$ and a $\mathrm{pH}$ value of 4.3 . The moisture values obtained are in agreement with results reported by Topal et al. [66] for olive stones ( $6.1 \mathrm{~g} / 100 \mathrm{~g}$ DW).

Table 4. Higher heating value (HHV) of crude olive pomace (C-OP) and olive pomace fractions produced after the wet and dry fractionation process (MJ/Kg DW).

\begin{tabular}{|c|c|c|c|c|c|c|c|}
\hline \multicolumn{8}{|c|}{ High Calorific Value (MJ/Kg Dry Weight) } \\
\hline \multicolumn{2}{|c|}{ C-OP } & \multicolumn{2}{|c|}{$\mathrm{P}+\mathrm{S}-\mathrm{OP}$} & \multicolumn{2}{|c|}{$\mathrm{P}-\mathrm{OP}$} & \multicolumn{2}{|c|}{ S-OP } \\
\hline OM 1 & OM 2 & OM 1 & OM 2 & OM 1 & OM 2 & OM 1 & OM 2 \\
\hline $20.57 \pm 0.03^{c, d}$ & $21.67 \pm 0.20^{\mathrm{b}}$ & $20.21 \pm 0.05^{\mathrm{d}}$ & $20.86 \pm 0.11^{\mathrm{c}}$ & $21.52 \pm 0.12^{b}$ & $22.21 \pm 0.01^{\mathrm{a}}$ & $18.94 \pm 0.00^{\mathrm{d}}$ & $18.65 \pm 0.00^{\mathrm{d}}$ \\
\hline
\end{tabular}

OM 1-Olive pomace from olive mill 1, OM 2-Olive pomace from olive mill 2, C-OP-Crude olive pomace; L-OP-liquid-rich fraction, $\mathrm{P}-\mathrm{OP}$ - pulp-rich fraction, $\mathrm{P}+\mathrm{S}-\mathrm{OP}$-Solid fraction without application of the dry fractionation. Data were expressed as mean $\pm \operatorname{SD}(n=3)$. The different superscripts in the same row represent significant differences between samples $(p<0.05)$. 
The values of $\mathrm{HHV}$, moisture and $\mathrm{pH}$ were measured to support the stones fraction application as solid biofuel. Besides, its character, being free of impurities (oil and low-weight particles), guarantees a better and safer combustion performance for this olive pomace fraction.

In the future, other compounds of stones (ash, chlorine, nitrogen, potassium, magnesium and phosphorus) need to be quantified in order to ensure its quality as a solid biofuel [12], as well as the possible use of binders and additives to improve the stability and the combustion characteristics of the stones fraction [68].

\subsection{Evaluation of the Fractionation Valorisation Approach for Olive Pomace in the Centre Region of Portugal: Case Study}

The present fractionation process has the potential to be a promising strategy for the whole valorisation of crude olive pomace at a large scale, due to being cheaper and more efficient regarding water and energy usage. To demonstrate the potential of the fractionation process proposed, we have considered the situation in the centre region of Portugal (third major olive oil producer region in Portugal), which represented around $15 \%$ of the national olive oil production in 2018 [35]. According to data from Instituto Nacional de Estatística (INE) [35], the production of olives used for olive oil extraction was of 62,280 tonnes in the centre region. It is estimated that approximately $35-40 \mathrm{~kg}$ of olive pomace is produced per $100 \mathrm{~kg}$ of olives [64], or, according to data of the most significant world producing regions of olive products (Andalusia), it represents approximately $65 \%$ of the initial weight [13]. So, at least 21,978 tonnes of crude olive pomace was generated in 2018, only in the centre region of Portugal.

Assuming the recovery of $80 \%$ of crude olive pomace through the selective collection in the centre region of Portugal, over 17,500 tonnes of crude olive pomace could be used to produce, on average: (1) 460 tonnes of enriched phenolic-mineral-sugar extract (liquid fraction) with a very significant recovery of hydroxytyrosol ( $53 \%)$, (2) 3440 tonnes of antioxidant fibre powder (pulp fraction) and also (3) 1200 tonnes of stones fraction with an HHV of about $19 \mathrm{MJ} / \mathrm{kg}$ that could be applied as solid biofuel (Figure 4). This study presents a highly promising methodology for the valorisation of crude olive pomace; however, a detailed cost-benefit analysis would be necessary to assess the economic feasibility of the proposed approach.

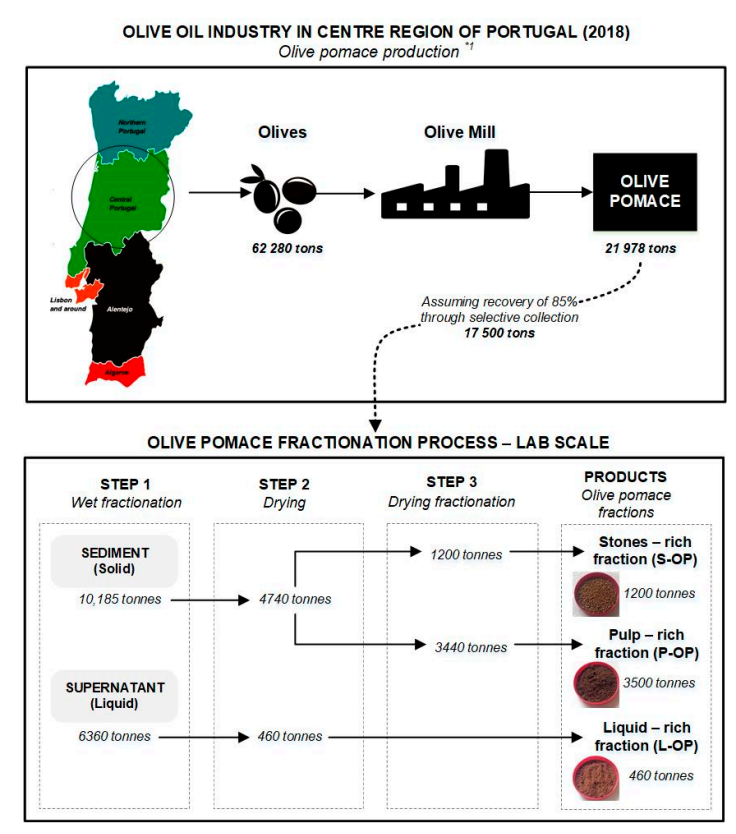

Figure 4. The yield of the fractionation process for olive pomace valorisation of the centre region of Portugal according to estimated production of 2018. 


\section{Conclusions}

This study demonstrated that a fractionation approach might constitute a new and promising route for converting olive pomace into multiple value-added products, like added-value energy applications without throwing away high-value compounds with food application. The first step (wet fractionation) leads to the production of a liquid fraction (yield of $9 \%$ in dry weight) rich in minerals $(\approx 11 \mathrm{~g} / 100 \mathrm{~g}$ ), sugars (mainly mannitol: $21-32 \mathrm{~g} / 100 \mathrm{~g}$ ), and phenolic compounds (mainly hydroxytyrosol: $514-626 \mathrm{mg} / 100 \mathrm{~g}$ ), but also has the advantage of optimising the drying process of the solid fraction. The dry fractionation allowed for attaining a stones fraction (yield of $20-26 \%$ in dry weight) with significant calorific power $(\sim 19 \mathrm{MJ} / \mathrm{kg}$ ) and a pulp fraction (yield of $65-71 \%$ in dry weight), which is a relevant source of antioxidant dietary fibre with a neutral detergent fibre content of 53-59 g/100 g and a significant antioxidant activity not only in free phenolics (ORAC: 455-503 $\mu \mathrm{M}$ trolox equivalents/g) but also in bound phenolics (ORAC: 121-130 $\mu \mathrm{M}$ trolox equivalents/g).

Considering the yield, the chemical composition and the in vitro antioxidant activity of both edible fractions, this approach allowed to obtain two sources of food ingredients: an enriched phenolic-mineral-sugar extract (liquid fraction) with potential application as a food preservative or health-promoting food ingredient, and a source of antioxidant dietary fibre (pulp fraction). At the same time, impurities such as the olive pulp and the small piece of stones related to emission, corrosion and slagging were removed to obtain a solid biofuel with better performance.

In the future, optimisation studies should be performed in combination with life cycle analysis (LCA) to improve the sustainability and economics of the fractionation approach proposed in this study. To guarantee the application of olive pomace fractions to develop new food ingredients, future studies about the safety, bioactivity and stability/bioaccessibility of its bioactive compounds will be necessary. At a pilot-scale, the replacement of the centrifugation without refrigeration and freeze-drying (adopted at the lab-scale) by mechanical pressing and conventional drying techniques respectively, could be feasible options to ensure a more affordable process.

Supplementary Materials: The following are available online at http://www.mdpi.com/2076-3417/10/19/6785/s1, Figure S1: Distribution (in percentage) of the phenolic compounds from olive pomace and its fractions identified by LC-ESI-UHR-QqTOF-MS.

Author Contributions: Conceptualisation, methodology, validation, formal analysis, M.P. and T.B.R.; Investigation, data curation, writing — original draft preparation, T.B.R.; Supervision, project administration, funding acquisition, writing-review and editing, M.P.; Supervision, writing-review and editing, A.A.V. and J.N.; Methodology, writing-review and editing, A.L.O. and C.C. All authors have read and agreed to the published version of the manuscript.

Funding: This research was funded by National Funds from FCT-Fundação para a Ciência e a Tecnologia, through the project MULTIBIOREFINERY-SAICTPAC/0040/2015 (POCI-01-0145-FEDER-016403) and the project “Biological tools for adding and defending value in key agro-food chains (bio-n2-value)", n ${ }^{\circ}$ NORTE-01-0145-FEDER-000030, funded by Fundo Europeu de Desenvolvimento Regional (FEDER), under Programa Operacional Regional do Norte-Norte2020. We would also like to thank the scientific collaboration under the FCT project UID/Multi/50016/2019.

Acknowledgments: T.B.R. thanks the Fundação para a Ciência e Tecnologia (FCT), Portugal for the PhD Grant SFRH/BDE/108271/2015 and the Grant financial support of BLC3 Association-Technology and Innovation Campus.

Conflicts of Interest: The authors declare no conflict of interest.

\section{References}

1. Ducom, G.; Gautier, M.; Pietraccini, M.; Tagutchou, J.-P.; Lebouil, D.; Gourdon, R. Comparative analyses of three olive mill solid residues from different countries and processes for energy recovery by gasification. Renew. Energy 2020, 145, 180-189. [CrossRef]

2. Torres-León, C.; Ramírez-Guzman, N.; Londoño-Hernandez, L.; Martinez-Medina, G.A.; Díaz-Herrera, R.; Navarro-Macias, V.; Alvarez-Pérez, O.B.; Picazo, B.; Villarreal-Vázquez, M.; Ascacio-Valdes, J.; et al. Food Waste and Byproducts: An Opportunity to Minimize Malnutrition and Hunger in Developing Countries. Front. Sustain. Food Syst. 2018, 2, 1-17. [CrossRef] 
3. Miranda, I.; Simões, R.; Medeiros, B.; Nampoothiri, K.M.; Sukumaran, R.K.; Rajan, D.; Pereira, H.; Ferreira-Dias, S. Valorization of lignocellulosic residues from the olive oil industry by production of lignin, glucose and functional sugars. Bioresour. Technol. 2019, 292, 121936. [CrossRef]

4. INE Previsões Agrícolas 31 de Janeiro 2020 Produção de Azeitona para Azeite com Máximo Histórico Ultrapassa as 940 mil Toneladas. 2020, pp. 1-5. Available online: https://www.ine.pt/xportal/xmain?xpid= INE\&xpgid=ine_destaques\&DESTAQUESdest_boui=399592136\&DESTAQUESmodo=2\&xlang=pt (accessed on 28 February 2020).

5. Nunes, M.A.; Costa, A.S.G.; Bessada, S.; Santos, J.; Puga, H.; Alves, R.C.; Freitas, V.; Oliveira, M.B.P.P. Olive pomace as a valuable source of bioactive compounds: A study regarding its lipid- and water-soluble components. Sci. Total Environ. 2018, 644, 229-236. [CrossRef]

6. Moreno-Maroto, J.M.; Uceda-Rodríguez, M.; Cobo-Ceacero, C.J.; de Hoces, M.C.; MartínLara, M.Á.; Cotes-Palomino, T.; López García, A.B.; Martínez -García, C. Recycling of 'alperujo' (olive pomace) as a key component in the sintering of lightweight aggregates. J. Clean. Prod. 2019, 239, 118041. [CrossRef]

7. Rubio-Senent, F.; Rodríguez-Gutíerrez, G.; Lama-Muñoz, A.; Fernández-Bolaños, J. New phenolic compounds hydrothermally extracted from the olive oil byproduct alperujo and their antioxidative activities. J. Agric. Food Chem. 2012, 60, 1175-1186. [CrossRef]

8. Nunes, M.A.; Pawlowski, S.; Costa, A.S.G.; Alves, R.C.; Oliveira, M.B.P.P.; Velizarov, S. Valorization of olive pomace by a green integrated approach applying sustainable extraction and membrane-assisted concentration. Sci. Total Environ. 2019, 652, 40-47. [CrossRef]

9. Salomone, R.; Ioppolo, G. Environmental impacts of olive oil production: A Life Cycle Assessment case study in the province of Messina (Sicily). J. Clean. Prod. 2012, 28, 88-100. [CrossRef]

10. Galanakis, C.M. Olive fruit dietary fiber: Components, recovery and applications. Trends Food Sci. Technol. 2011, 22, 175-184. [CrossRef]

11. Mata-Sánchez, J.; Pérez-Jiménez, J.A.; Díaz-Villanueva, M.J.; Serrano, A.; Núñez-Sánchez, N.; López-Giménez, F.J. Corrosive properties prediction from olive byproducts solid biofuel by near infrared spectroscopy. Energy Fuels 2014, 28, 5136-5143. [CrossRef]

12. Mata Sánchez, J.; Pérez Jiménez, J.A.; Díaz Villanueva, M.J.; Serrano, A.; Núñez, N.; López Giménez, J. New techniques developed to quantify the impurities of olive stone as solid biofuel. Renew. Energy 2015, 78, 566-572. [CrossRef]

13. AGAPA Evaluación de la Producción y Usos de los Subproductos de las Agroindustrias del Olivar en Andalucía. Cons. Agric. Pesca y Desarro. 2015. Available online: https://www.juntadeandalucia.es/agriculturaypesca/ observatorio/servlet/FrontController?ec=default\&action=DownloadS\&table=11030\&element=1585171\& field=DOCUMENTO (accessed on 28 February 2020).

14. Berbel, J.; Posadillo, A. Review and Analysis of Alternatives for the Valorisation of Agro-Industrial Olive Oil By-Products. Sustainability 2018, 10, 237. [CrossRef]

15. Roselló-Soto, E.; Koubaa, M.; Moubarik, A.; Lopes, R.P.; Saraiva, J.A.; Boussetta, N.; Grimi, N.; Barba, F.J. Emerging opportunities for the effective valorization of wastes and by-products generated during olive oil production process: Non-conventional methods for the recovery of high-added value compounds. Trends Food Sci. Technol. 2015, 45, 296-310. [CrossRef]

16. Pérez-Jiménez, J.; Díaz-Rubio, M.E.; Saura-Calixto, F. Obtainment and characterization of a potential functional ingredient from olive. Int. J. Food Sci. Nutr. 2015, 66, 749-754. [CrossRef] [PubMed]

17. Ying, D.Y.; Hlaing, M.M.; Lerisson, J.; Pitts, K.; Cheng, L.; Sanguansri, L.; Augustin, M.A. Physical properties and FTIR analysis of rice-oat flour and maize-oat flour based extruded food products containing olive pomace. Food Res. Int. 2017, 100, 665-673. [CrossRef]

18. Delisi, R.; Ciriminna, R.; Arvati, S.; Meneguzzo, F.; Pagliaro, M. Olive biophenol integral extraction at a two-phase olive mill. J. Clean. Prod. 2018, 174, 1487-1491. [CrossRef]

19. Quirós-Sauceda, A.E.; Palafox-Carlos, H.; Sáyago-Ayerdi, S.G.; Ayala-Zavala, J.F.; Bello-Perez, L.A.; Álvarez-Parrilla, E.; de la Rosa, L.A.; González-Córdova, A.F.; González-Aguilar, G.A. Dietary fiber and phenolic compounds as functional ingredients: Interaction and possible effect after ingestion. Food Funct. 2014, 5, 1063-1072. [CrossRef]

20. Alu'datt, M.H.; Rababah, T.; Ereifej, K.; Alli, I. Distribution, antioxidant and characterisation of phenolic compounds in soybeans, flaxseed and olives. Food Chem. 2013, 139, 93-99. [CrossRef] 
21. Helrich, K. Official Methods of Analysis of the Association of Official Analytical Chemists (AOAC); Association of Official Analytical Chemists Inc.: Washington, DC, USA, 1990; ISBN 0-935584-42-0.

22. Goering, H.K.; Van Soest, P.J. Forage Fiber Analysis (Apparatus, Procedures and Some Applications). Agric. Handb. 1970, 379, 5-11.

23. Sluiter, A.; Hames, B.; Ruiz, R.; Scarlata, C.; Sluiter, J.; Templeton, D.; Crocker, D. NREL/TP-510-42618 Analytical Procedure-Determination of Structural Carbohydrates and Lignin in Biomass; NREL, 2012; Volume 17. Available online: https://www.nrel.gov/docs/gen/fy13/42618.pdf (accessed on 18 March 2018).

24. Sluiter, A.; Ruiz, R.; Scarlata, C.; Sluiter, J.; Templeton, D. Determination of Extractives in Biomass: Laboratory Analytical Procedure (LAP); Issue Date 7/17/2005-42619; NREL, 2008. Available online: https://www.nrel.gov/ docs/gen/fy08/42619.pdf (accessed on 18 March 2018).

25. Deng, Q.; Penner, M.H.; Zhao, Y. Chemical composition of dietary fiber and polyphenols of five different varieties of wine grape pomace skins. Food Res. Int. 2011, 44, 2712-2720. [CrossRef]

26. Nielsen, S.S. Phenol-Sulfuric Acid Method for Total Carbohydrates; Springer: Boston, MA, USA, 2010; pp. 47-53.

27. Campos, D.A.; Ribeiro, T.B.; Teixeira, J.A.; Pastrana, L.; Pintado, M.M. Integral Valorization of Pineapple (Ananas comosus L.) By-Products through a Green Chemistry Approach towards Added Value Ingredients. Foods 2020, 9, 60. [CrossRef] [PubMed]

28. Xie, P.-J.; Huang, L.-X.; Zhang, C.; Zhang, Y.-L. Phenolic compositions, and antioxidant performance of olive leaf and fruit (Olea europaea L.) extracts and their structure-activity relationships. J. Funct. Foods 2015, 16, 460-471. [CrossRef]

29. Oliveira, A.L.; von Staszewski, M.; Pizones Ruiz-Henestrosa, V.M.; Pintado, M.; Pilosof, A.M.R. Impact of pectin or chitosan on bulk, interfacial and antioxidant properties of $(+)$-catechin and $\beta$-lactoglobulin ternary mixtures. Food Hydrocoll. 2016, 55, 119-127. [CrossRef]

30. Monforte, A.R.; Martins, S.I.F.S.; Silva Ferreira, A.C. Strecker Aldehyde Formation in Wine: New Insights into the Role of Gallic Acid, Glucose, and Metals in Phenylacetaldehyde Formation. J. Agric. Food Chem. 2018, 66, 2459-2466. [CrossRef]

31. Oliveira, C.M.; Barros, A.S.; Silva Ferreira, A.C.; Silva, A.M.S. Influence of the temperature and oxygen exposure in red Port wine: A kinetic approach. Food Res. Int. 2015, 75, 337-347. [CrossRef]

32. Alexandre, E.M.C.; Silva, S.; Santos, S.A.O.; Silvestre, A.J.D.; Duarte, M.F.; Saraiva, J.A.; Pintado, M. Antimicrobial activity of pomegranate peel extracts performed by high pressure and enzymatic assisted extraction. Food Res. Int. 2019, 115, 167-176. [CrossRef]

33. Cano, A.; Acosta, M.; Arnao, M.B. A method to measure antioxidant activity in organic media: Application to lipophilic vitamins. Redox Rep. 2000, 5, 365-370. [CrossRef]

34. Pontes, R.; Romaní, A.; Michelin, M.; Domingues, L.; Teixeira, J.; Nunes, J. Comparative autohydrolysis study of two mixtures of forest and marginal land resources for co-production of biofuels and value-added compounds. Renew. Energy 2018, 128, 20-29. [CrossRef]

35. INE. Estatísticas Agrícolas 2018; INE: Lisboa, Portugal, 2019; ISBN 9789892504957. Available online: https://www.ine.pt/xportal/xmain?xpid=INE\&xpgid=ine_publicacoes\&PUBLICACOESpub_boui= 383058708\&PUBLICACOESmodo=2\&xlang=pt (accessed on 16 March 2020).

36. Venkata Mohan, S.; Dahiya, S.; Amulya, K.; Katakojwala, R.; Vanitha, T.K. Can circular bioeconomy be fueled by waste biorefineries-A closer look. Bioresour. Technol. Reports 2019, 7, 100277. [CrossRef]

37. Aggoun, M.; Arhab, R.; Cornu, A.; Portelli, J.; Barkat, M.; Graulet, B. Olive mill wastewater microconstituents composition according to olive variety and extraction process. Food Chem. 2016, 209, 72-80. [CrossRef]

38. Uribe, E.; Lemus-Mondaca, R.; Vega-Gálvez, A.; Zamorano, M.; Quispe-Fuentes, I.; Pasten, A.; Di Scala, K. Influence of process temperature on drying kinetics, physicochemical properties and antioxidant capacity of the olive-waste cake. Food Chem. 2014, 147, 170-176. [CrossRef] [PubMed]

39. Conde, C.; Delrot, S.; Gerós, H. Physiological, biochemical and molecular changes occurring during olive development and ripening. J. Plant Physiol. 2008, 165, 1545-1562. [CrossRef]

40. Van Soest, P.J.; Robertson, J.B.; Lewis, B.A. Methods for Dietary Fiber, Neutral Detergent Fiber, and Nonstarch Polysaccharides in Relation to Animal Nutrition. J. Dairy Sci. 1991, 74, 3583-3597. [CrossRef]

41. Sedlmeyer, F.B. Xylan as by-product of biorefineries: Characteristics and potential use for food applications. Food Hydrocoll. 2011, 25, 1891-1898. [CrossRef] 
42. Sato, Y.; Itagaki, S.; Kurokawa, T.; Ogura, J.; Kobayashi, M.; Hirano, T.; Sugawara, M.; Iseki, K. In vitro and in vivo antioxidant properties of chlorogenic acid and caffeic acid. Int. J. Pharm. 2011, 403, 136-138. [CrossRef] [PubMed]

43. Dong, X.; Dong, M.; Lu, Y.; Turley, A.; Jin, T.; Wu, C. Antimicrobial and antioxidant activities of lignin from residue of corn stover to ethanol production. Ind. Crops Prod. 2011, 34, 1629-1634. [CrossRef]

44. Rubio-Senent, F.; Rodríguez-Gutiérrez, G.; Lama-Muñoz, A.; García, A.; Fernández-Bolaños, J. Novel pectin present in new olive mill wastewater with similar emulsifying and better biological properties than citrus pectin. Food Hydrocoll. 2015, 50, 237-246. [CrossRef]

45. Gómez-González, S.; Ruiz-Jiménez, J.; Priego-Capote, F.; Luque De Castro, M.D. Qualitative and quantitative sugar profiling in olive fruits, leaves, and stems by gas chromatography-tandem mass spectrometry (GC-MS/MS) after ultrasound-assisted leaching. J. Agric. Food Chem. 2010, 58, 12292-12299. [CrossRef]

46. Babich, O.; Dyshlyuk, L.; Noskova, S.; Sukhikh, S.; Prosekov, A.; Ivanova, S.; Pavsky, V. In vivo study of the potential of the carbohydrate-mineral complex from pine nut shells as an ingredient of functional food products. Bioact. Carbohydrates Diet. Fibre 2019, 18, 100185. [CrossRef]

47. Fitch, C.; Keim, K.S. Position of the Academy of Nutrition and Dietetics: Use of Nutritive and Nonnutritive Sweeteners. J. Acad. Nutr. Diet. 2012, 112, 739-758. [CrossRef]

48. Ghoreishi, S.M.; Shahrestani, R.G. Subcritical water extraction of mannitol from olive leaves. J. Food Eng. 2009, 93, 474-481. [CrossRef]

49. Uncu, O.; Ozen, B.; Tokatli, F. Use of FTIR and UV-visible spectroscopy in determination of chemical characteristics of olive oils. Talanta 2019, 201, 65-73. [CrossRef] [PubMed]

50. Lopez-Huertas, E. Health effects of oleic acid and long chain omega-3 fatty acids (EPA and DHA) enriched milks. A review of intervention studies. Pharmacol. Res. 2010, 61, 200-207. [CrossRef] [PubMed]

51. Fakharedine, N.; El Hajjouji, H.; Ait Baddi, G.; Revel, J.C.; Hafidi, M. Chemical and spectroscopic analysis of organic matter transformation during aerobic digestion of olive-mill waste-waters. Process Biochem. 2006, 41, 398-404. [CrossRef]

52. Cioffi, G.; Pesca, M.S.; De Caprariis, P.; Braca, A.; Severino, L.; De Tommasi, N. Phenolic compounds in olive oil and olive pomace from Cilento (Campania, Italy) and their antioxidant activity. Food Chem. 2010, 121, 105-111. [CrossRef]

53. Gouvinhas, I.; Domínguez-Perles, R.; Gironés-Vilaplana, A.; Carvalho, T.; Machado, N.; Barros, A. Kinetics of the Polyphenolic Content and Radical Scavenging Capacity in Olives through On-Tree Ripening. J. Chem. 2017, 2017, 1-11. [CrossRef]

54. Capriotti, A.L.; Cavaliere, C.; Crescenzi, C.; Foglia, P.; Nescatelli, R.; Samperi, R.; Laganà, A. Comparison of extraction methods for the identification and quantification of polyphenols in virgin olive oil by ultra-HPLC-QToF mass spectrometry. Food Chem. 2014, 158, 392-400. [CrossRef]

55. Peralbo-Molina, Á.; Priego-Capote, F.; Luque De Castro, M.D. Tentative identification of phenolic compounds in olive pomace extracts using liquid chromatography-tandem mass spectrometry with a quadrupolequadrupole-time-of-flight mass detector. J. Agric. Food Chem. 2012, 60, 11542-11550. [CrossRef]

56. Jerman Klen, T.; Mozetič Vodopivec, B. The fate of olive fruit phenols during commercial olive oil processing: Traditional press versus continuous two- and three-phase centrifuge. LWT Food Sci. Technol. 2012, 49, 267-274. [CrossRef]

57. Obied, H.K.; Bedgood, D.R.; Prenzler, P.D.; Robards, K. Bioscreening of Australian olive mill waste extracts: Biophenol content, antioxidant, antimicrobial and molluscicidal activities. Food Chem. Toxicol. 2007, 45, 1238-1248. [CrossRef]

58. EFSA Scientific Opinion on the substantiation of health claims related to polyphenols in olive and protection of LDL particles from oxidative damage (ID 1333, 1638, 1639, 1696, 2865), maintenance of normal blood HDL cholesterol concentrations (ID 1639), mainte. EFSA J. 2011, 9, 2033.

59. Dang, H.; Meng, M.H.W.; Zhao, H.; Iqbal, J.; Dai, R.; Deng, Y.; Lv, F. Luteolin-loaded solid lipid nanoparticles synthesis, characterization, \& improvement of bioavailability, pharmacokinetics in vitro and vivo studies. J. Nanopart. Res. 2014, 16, 2347.

60. Aziz, N.; Kim, M.-Y.; Cho, J.Y. Anti-inflammatory effects of luteolin: A review of in vitro, in vivo, and in silico studies. J. Ethnopharmacol. 2018, 225, 342-358. [CrossRef] [PubMed] 
61. Nieto Calvache, J.; Cueto, M.; Farroni, A.; de Escalada Pla, M.; Gerschenson, L.N. Antioxidant characterization of new dietary fiber concentrates from papaya pulp and peel (Carica papaya L.). J. Funct. Foods 2016, 27, 319-328. [CrossRef]

62. Rasouli, H.; Hosseini-Ghazvini, S.M.-B.; Adibi, H.; Khodarahmi, R. Differential $\alpha$-amylase/ $\alpha$-glucosidase inhibitory activities of plant-derived phenolic compounds: A virtual screening perspective for the treatment of obesity and diabetes. Food Funct. 2017, 8, 1942-1954. [CrossRef] [PubMed]

63. Bezerra, C.F.; Camilo, C.J.; do Nascimento Silva, M.K.; de Freitas, T.S.; Ribeiro-Filho, J.; Coutinho, H.D.M. Vanillin selectively modulates the action of antibiotics against resistant bacteria. Microb. Pathog. 2017, 113, 265-268. [CrossRef]

64. de Rezende Mudenuti, N.V.; de Camargo, A.C.; Shahidi, F.; Madeira, T.B.; Hirooka, E.Y.; Grossmann, M.V.E. Soluble and insoluble-bound fractions of phenolics and alkaloids and their antioxidant activities in raw and traditional chocolate: A comparative study. J. Funct. Foods 2018, 50, 164-171. [CrossRef]

65. Gong, L.; Cao, W.; Chi, H.; Wang, J.; Zhang, H.; Liu, J.; Sun, B. Whole cereal grains and potential health effects: Involvement of the gut microbiota. Food Res. Int. 2018, 103, 84-102. [CrossRef]

66. Topal, H.; Taner, T.; Naqvi, S.A.H.; Altınsoy, Y.; Amirabedin, E.; Ozkaymak, M. Exergy analysis of a circulating fluidized bed power plant co-firing with olive pits: A case study of power plant in Turkey. Energy 2017, 140, 40-46. [CrossRef]

67. Vamvuka, D.; Kakaras, E. Ash properties and environmental impact of various biomass and coal fuels and their blends. Fuel Process. Technol. 2011, 92, 570-581. [CrossRef]

68. Christoforou, E.; Fokaides, P.A. A review of olive mill solid wastes to energy utilization techniques. Waste Manag. 2016, 49, 346-363. [CrossRef] [PubMed]

(C) 2020 by the authors. Licensee MDPI, Basel, Switzerland. This article is an open access article distributed under the terms and conditions of the Creative Commons Attribution (CC BY) license (http://creativecommons.org/licenses/by/4.0/). 